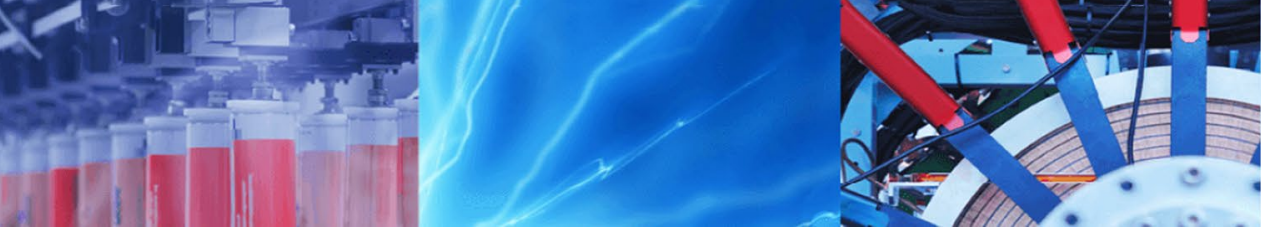

Research Article

\title{
Photodegradation of methylene blue under direct sunbeams by synthesized anatase titania nanoparticles
}

\author{
Amar Kundu $^{1}$ (D) Aparna Mondal ${ }^{1}$
}

(c) Springer Nature Switzerland AG 2019

\begin{abstract}
Surfactant-assisted titania nanoparticles have been successfully synthesized using an inorganic salt of titanium by controlled hydrolysis method. Anionic (Sodium dodecyl sulfate), nonionic (Brij C10) and cationic (Dodecyl amine) surfactants have been used to synthesize the titania nanoparticles. The XRD patterns of the $500^{\circ} \mathrm{C}$ annealed nanoparticles exhibit technologically important anatase phase. Anatase to rutile transformation is observed for Ti-D-650 nanoparticles at lower temperature. It has been observed that the Ti-S-900 nanoparticles retained to the anatase phase at higher temperature up to $900^{\circ} \mathrm{C}$. The Brij C10 assisted nanoparticles (Ti-B-500) exhibited high surface area and lower crystallite size compared to other nanoparticles. In addition, Ti-B-500 samples exhibited wormlike mesopores structure. XPS study confirmed the presence of sulphur in Ti-B-500 nanoparticles, which creates an O-S mixed environment into the lattice. The nanoparticles also showed a red shift in the UV-DRS study with a lower band gap (indirect) energy about $3.02 \mathrm{eV}$. Impedance spectrum of the Ti-B-500 nanoparticles confirmed the enhanced electron-hole separation rate involved in the photodegradation process. Photodegradation rate of methylene blue $\left[2 \times 10^{-5}(\mathrm{M})\right]$ with Ti-B-500 nanoparticles under direct sunbeams has been observed to be higher compared to other surfactant-assisted nanoparticles. The rate of photodegradation is found to be best at $\mathrm{pH}=6.7$ with a rate of $0.0864 \mathrm{~min}^{-1}$ and the catalyst showed best reusability even after five cycles of experiment.
\end{abstract}

Keywords Titania $\cdot$ Mesoporous $\cdot$ Surfactants $\cdot$ Photocatalysis

\section{Introduction}

Now a days, considerable attention has been devoted on developing clean and ecological energy sources owing to the cumulative energy and environmental challenges [1-7]. Solar energy has the potential to produce a green and environmentally friendly society and by using it, numerous research devoted to empowering the transformation of solar energy into operational energy. Solar energy is being used in solar cells, photocatalysis, photo-electrochemical cells, and in other various applications [8-12]. Among various semiconductors, titania $\left(\mathrm{TiO}_{2}\right)$ has always been the one widely studied due to its chemical stability, water insolubility, low cost, promising photo-chemical property and non-toxic nature [13-16]. It has also been used intensively as a photocatalyst for wide range of applications along with $\mathrm{H}_{2}$-generation, $\mathrm{CO}_{2}$ reduction and in environmental remediation [17-19]. Over the past few decades, researchers have given remarkable efforts to improve the photocatalytic activity of $\mathrm{TiO}_{2}$-based materials [20-24]. According to the literature, to improve the photocatalytic activity, generation, migration, and separation of photogenerated electrons and holes are essential which can be achieved by preparing high crystalline small $\mathrm{TiO}_{2}$ crystals $[25,26]$. Anatase phase of $\mathrm{TiO}_{2}$ is mostly used as photocatalyst over rutile $\mathrm{TiO}_{2}$ because of higher redox potential and lower electron-hole pair recombination rate [27]. However, anatase to rutile phase transformation occurs just above $600{ }^{\circ} \mathrm{C}$ due to thermodynamically metastable nature of the anatase phase. Therefore, preparing stable anatase $\mathrm{TiO}_{2}$

Amar Kundu, amarchem10@gmail.com | 'Department of Chemistry, National Institute of Technology, Rourkela, Odisha 769008, India.

SN Applied Sciences (2019) 1:280 | https://doi.org/10.1007/s42452-019-0280-3 
nanoparticles with higher crystallinity by thermal treatment is bit difficult [28]. Earlier, numerous procedures are developed to produce $\mathrm{TiO}_{2}$ nanoparticles with controlled shape, size and porosity for use in ceramics, composites, thin films, and catalysts [29-35]. Today various methods such as sol-gel, micelle and inverse micelle, hydrothermal, solvothermal, direct oxidation, chemical and physical vapor deposition, electrodeposition, sonochemical, microwave, ultrasonic spray pyrolysis and so on have been developed to synthesize $\mathrm{TiO}_{2}$ nanoparticles [36-45]. Among the above mentioned methods, the micelle and inverse micelle (also known as microemulsion method) approaches are costeffective and energy efficient to produce nanometer-sized particles and porous materials [46-49]. The important feature of these methods is to constrain the reactions in the nano-reactors core of reverse micelles, which control the particle size and porosity generated when the micelles are intact in solution and removed during calcination.

In this work, the $\mathrm{TiO}_{2}$ nanoparticles are synthesized with and without different surfactant templates (anionic, non-ionic and cationic) to utilize the nanoparticles for photodegradation of organic dye molecules. Moreover, the experiment is carried out under direct sunlight to use the catalyst in real time applications.

\section{Experimental section}

\subsection{Chemicals used}

Titanium (IV) oxysulphate $\left(\mathrm{TiOSO}_{4}\right.$ ) (as a $\mathrm{TiO}_{2}$ precursor) and Brij $\mathrm{C} 10$ have been procured from Aldrich Chemicals. Sodium dodecyl sulphate (SDS), dodecylamine (DDA), Ammonia solution (about 25\%) (as precipitating agent), isopropanol and ethanol have been procured from Merck Chemicals. All chemicals were of analytical reagent grade and used without any additional purification. Deionized water from ELGA PURELAB Option-Q water purification system has been used during the synthesis.

\subsection{Preparation of titania nanoparticles}

Titania nanoparticles have been prepared by controlled precipitation of the precursor by ammonia solution in presence of surfactant templates. In a typical procedure, the surfactant solutions are prepared separately as follows; Sodium dodecyl sulfate (SDS), dodecyl amine (DDA) are dissolved in water and Brij C10 (average $M_{n} \sim 683$ ) in isopropanol at $15 \mathrm{wt} \%$ ratio and stirred constantly for $30 \mathrm{~min}$. Different surfactant solutions are added dropwise separately to each set of $0.5(\mathrm{M})$ precursor solution followed by constant stirring for $1 \mathrm{~h}$. Then to each set of mixed solution (precursor and surfactant solutions), $\mathrm{NH}_{4} \mathrm{OH}$ solution (30 vol\%) is added slowly to obtain the precipitate until the $\mathrm{pH}$ of the solutions becomes 7. The resulting precipitates are kept under aging about 2 days at room temperature. The precipitates are filtered and washed with distilled water for numerous times and through ethanol 4-5 times to remove excess surfactants and other impurities. The subsequent precipitates are dried in oven at $60^{\circ} \mathrm{C}$ and then calcined at $500^{\circ} \mathrm{C}, 650^{\circ} \mathrm{C}$ and $900^{\circ} \mathrm{C}$ in air atmosphere at a heating rate of $4 \% \mathrm{~min}$ for $2 \mathrm{~h}$. For evaluation purpose, $\mathrm{TiO}_{2}$ samples are prepared using the same procedure without surfactant template. The synthesized powders are assigned as " $\mathrm{Ti}-(\mathrm{S}, \mathrm{B}$, and $\mathrm{D})-\mathrm{T}$ ". S-represent sodium dodecyl sulphate, $B$-represent Brij C10, Drepresent dodecylamine, and $\mathrm{T}$-represent the annealed temperatures. The titania nanopowder synthesized without surfactant template is named as Ti-T.

\subsection{Chemical characterization of nanoparticles}

In order to analyze the phase formation or crystallization $\mathrm{X}$-ray diffraction has been carried out at room temperature in Rigaku Ultima IV X-ray diffractometer using $0.154056 \mathrm{~nm}$ $\mathrm{Cu}-\mathrm{Ka}$ radiation. Rietveld refinement is carried out with the help of Full Prof Suite using standard lattice parameters, cell volume, Wyckoff positions and Pseudo-Voight profile function is used to refine the XRD patterns. First, using linear interpolation method, background data has been created and the scale factor, zero correction, displacement, lattice parameters, full-width half-maximum (FWHM) parameter, and Wyckoff positions are refined one by one to acquire the best fit. The occupancy of all the atomic sites are kept fixed during the process. We have carried out the refinement and other characteristic measurement for the $500^{\circ} \mathrm{C}$ annealed nanoparticles because these samples only hold the pure anatase phase. The Scherrer's equation is applied to estimate the crystallite size using FWHM of the (101) peak of anatase. Raman spectra are recorded in Witec Alpha-300 Confocal Raman microscope using solid-state laser source with an excitation line of $532 \mathrm{~nm} . \mathrm{N}_{2}$ adsorption/desorption isotherms are obtained on a Quantachrome Autosorb-1 apparatus after degassing the samples at $200^{\circ} \mathrm{C}$ for $2 \mathrm{~h}$ at relative pressure range $0.03-1.00$. High-Resolution micrographs of the annealed samples are recorded using FEI Tecnai F30 S-TWIN equipped with QANTEX EDS detector. The band gap energy of the nanoparticles is calculated from Kubelka-Munk equation using UV-vis diffuse reflectance spectra (UV-vis DRS), taken with $\mathrm{BaSO}_{4}$ as reflectance standard in UV-2450 Shimadzu spectrometer equipped with an integrating sphere assembly. $X$-ray photoelectron spectra (XPS) are studied by Photoemission Electron Spectroscopy (PES) beamline BL-14 of the Indus- 2 synchrotron source in an 
ultrahigh vacuum with the source of monochromatic X-ray beam energy of $4357 \mathrm{eV}$. A double-crystal $\mathrm{Si}$ (111) monochromator and SPECS in the PHOIBOS $225 \mathrm{HV}$ hemispherical electron energy analyzer has been used to record the spectra. The binding energy (BE) is calibrated using the $C 1$ s peak. Electrical measurements are carried out with sample pellets. To prepare the pellets first, the nanoparticles are mixed with a binder (PVA= polyvinyl alcohol) and shaped in the pellet form. Then the pellets are heated at $400^{\circ} \mathrm{C}$ for $2 \mathrm{~h}$ to remove the binder. The pellets are then polished with emery paper and cleaned using acetone. To make an electrode, the pellets are coated with silver paint on both surfaces and then dried at $150{ }^{\circ} \mathrm{C}$ for $2 \mathrm{~h}$ to remove the moisture present in the samples. In this investigation HIOKI IM -3570 Impedance analyzer with a computer set up is used in the frequency range $100 \mathrm{~Hz}-1 \mathrm{MHz}$ to collect the data. The impedance data are fitted using Zview2 software.

\subsection{The photocatalytic activity and recyclability tests}

The photocatalytic effectiveness of all the nanoparticles are evaluated by the extent of degradation of methylene blue (MB) in an aqueous solution under direct solar light irradiation without maintaining the intensity of sunlight during subsequent reactions. In a typical experiment, a $200 \mathrm{~mL}$ of $2 \times 10^{-5}(\mathrm{M}) \mathrm{MB}$ solution was taken in a $500 \mathrm{ml}$ beaker to which photocatalysts of $200 \mathrm{mg}(1 \mathrm{~g} / \mathrm{L})$ were added separately with vigorous stirring. An aliquot of the solution is taken to measure the concentration of the adsorbed dye after $30 \mathrm{~min}$. of adsorption-desorption equilibrium in the dark. Then the dye solutions are set aside under sunlight at room temperature for the photodegradation process to take place. Sample aliquots are withdrawn from the reaction mixture at $10 \mathrm{~min}$. time interval and then centrifuged. The dye concentration of the residual solution is analyzed using UV-Vis spectrophotometer. Changes in the MB concentration are measured from its characteristic absorption band maximum ( $\lambda_{\max }=663 \mathrm{~nm}$ ). To find out the effect of $\mathrm{pH}$ on photodegradation, we have adjusted acidity and basicity of the dye solution using hydrochloric acid $(\mathrm{HCl})$ and sodium hydroxide $(\mathrm{NaOH})$, respectively. Effect of catalyst loading on the photodegradation process is also investigated. Moreover, we have examined the catalytic activity on photodegradation by repeating it for five cycles of experiment.

\section{Results and discussion}

\subsection{X-ray diffraction}

Figure 1a shows the X-ray diffraction (XRD) pattern of $500{ }^{\circ} \mathrm{C}$ calcined $\mathrm{TiO}_{2}$ nanoparticles, which manifest the formation of anatase phase (tetragonal) with absence of any secondary phase. The XRD pattern of anatase phase is well matched with the JCPDS card no. 21-1272 and the basic parameters from the JCPDS are used for the refinement. The presented refinement patterns shows a good reasonable fit between the experimental and simulated data. The obtained refined parameters are shown in Table 1. XRD patterns of $650^{\circ} \mathrm{C}$ calcined titania nanoparticles are presented in Fig. $1 \mathrm{~b}$. The results indicate more sharp peaks, which specifies the formation of higher crystalline particles. Except Ti-D-650, all other $650^{\circ} \mathrm{C}$ annealed nanoparticles retained to the anatase phase. Moreover, the results show that DDA templating actually helps in increasing the anatase to rutile transformation at lower temperature. The Ti-D-650 nanoparticles contain anatase and rutile phases with $81 \%$ and $19 \%$, respectively. The content of anatase phase is calculated using Eq. 1, where $F_{A^{\prime}} I_{A^{\prime}}$ and $I_{R}$ represent percentage of anatase phase, intensity of the anatase peak and intensity of rutile peak respectively. Figure $1 \mathrm{C}$ represents the XRD profile of $900{ }^{\circ} \mathrm{C}$ annealed nanoparticles. The data indicates that except Ti-S-900, the other nanoparticles have transformed from anatase to rutile phase fully or partially. The Ti-S-900 nanoparticles retained to anatase phase at higher temperature up to $900^{\circ} \mathrm{C}$. Best to the author's knowledge, anatase phase stability at that higher temperature in pure titania till now not has been reported. Steven J. Hinder et al. reported pure anatase phase stability up to $850^{\circ} \mathrm{C}$ [50]. Crystallite sizes $\left(D_{\text {hkl }}\right)$ of the nanoparticles have been calculated using the Scherrer's Equation (Eq. 2), where " $\lambda$ " is the wavelength and " $\beta_{h k l}$ " is the full width at half maximum. Among the $500^{\circ} \mathrm{C}$ calcined particles, Ti-B-500 formed the lower crystallite size about $8.0 \mathrm{~nm}$. The crystallite size (anatase lattice) of all nanoparticles are presented in Table 1.

$$
\begin{aligned}
& \mathrm{F}_{\mathrm{A}}=100-\left(\frac{1}{1+0.8\left(\mathrm{I}_{\mathrm{A}}(101) / \mathrm{I}_{\mathrm{R}}(110)\right.}\right) 100 \\
& \mathrm{D}_{\text {hkl }}=\left[\frac{0.9 \lambda}{\beta_{h k l} \operatorname{Cos} \theta}\right]
\end{aligned}
$$

\subsection{Raman analysis}

Structural phase of $\mathrm{TiO}_{2}$ nanoparticles is further investigated using Raman spectroscopy. Figure 2 displays the Raman shifts profile in $\mathrm{TiO}_{2}$ nanoparticles. The scattering bands are located at 148.4-151.3 $\left(E_{g}\right), 397.1-401.6\left(B_{1 g}\right)$, 520.8-525.2 $\left(B_{1 \mathrm{~g}}+A_{1 g}\right)$, and 642.4-645.6 $\mathrm{cm}^{-1}\left(E_{\mathrm{g}}\right)$, corresponding to the characteristic peaks of anatase phase of $\mathrm{TiO}_{2}$. The $\mathrm{E}_{\mathrm{g}}$ mode is due to the symmetric stretching vibration of $\mathrm{O}-\mathrm{Ti}-\mathrm{O}$, the $\mathrm{B}_{1 \mathrm{~g}}$ mode is associated with symmetric bending vibrations of $\mathrm{O}-\mathrm{Ti}-\mathrm{O}$ in $\mathrm{TiO}_{2}$, and 
Fig. 1 Powder X-ray diffraction (PXRD) pattern of $\mathbf{a} 500^{\circ} \mathrm{C}$ (Rietveld refined) $\mathbf{b} 650^{\circ} \mathrm{C}$ and $\mathrm{c} 900^{\circ} \mathrm{C}$ calcined titania nanoparticles
Table 1 Rietveld refined parameters (only $500{ }^{\circ} \mathrm{C}$ heated samples) and crystallite size of prepared titania nanoparticles (a)
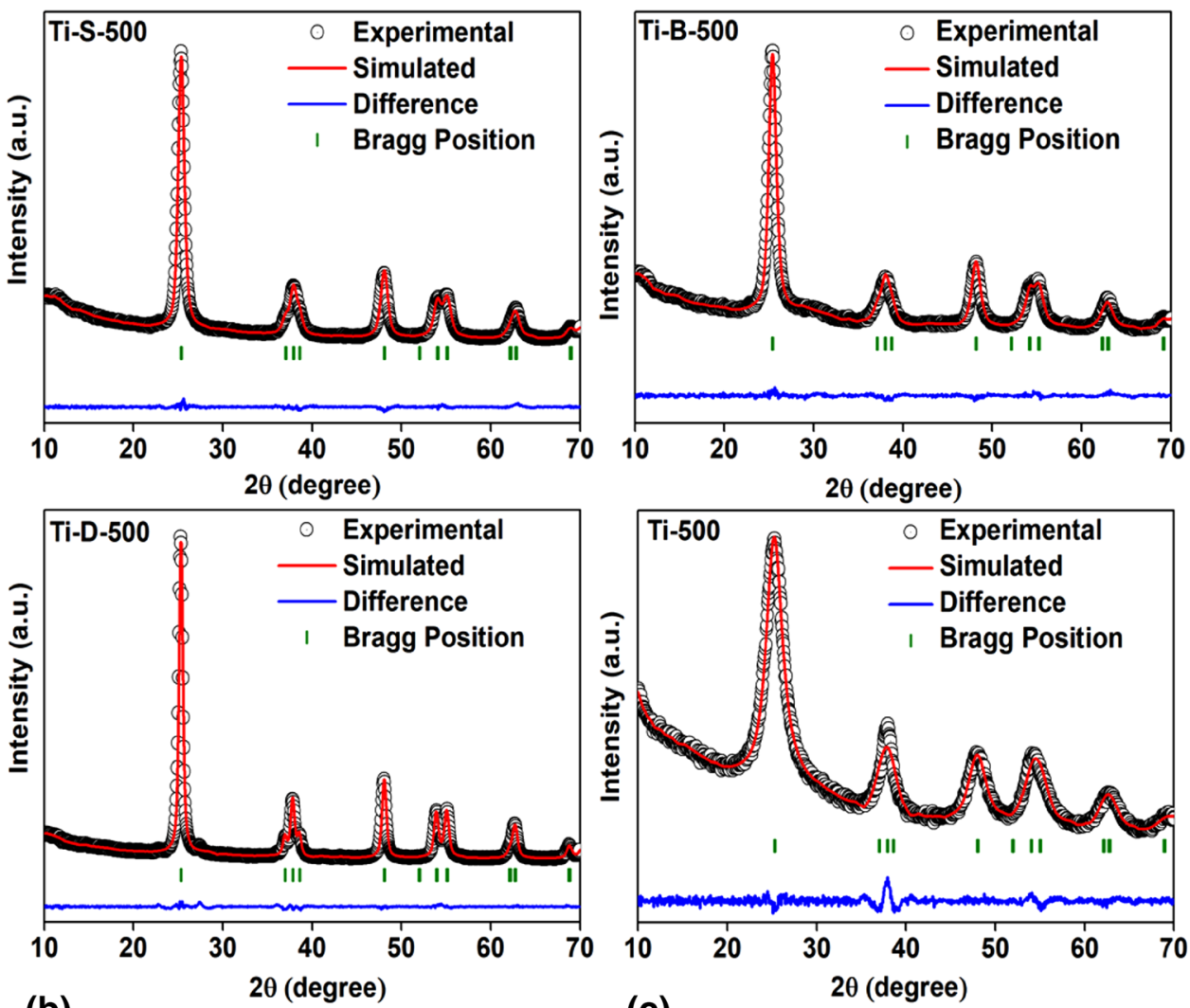

(c)
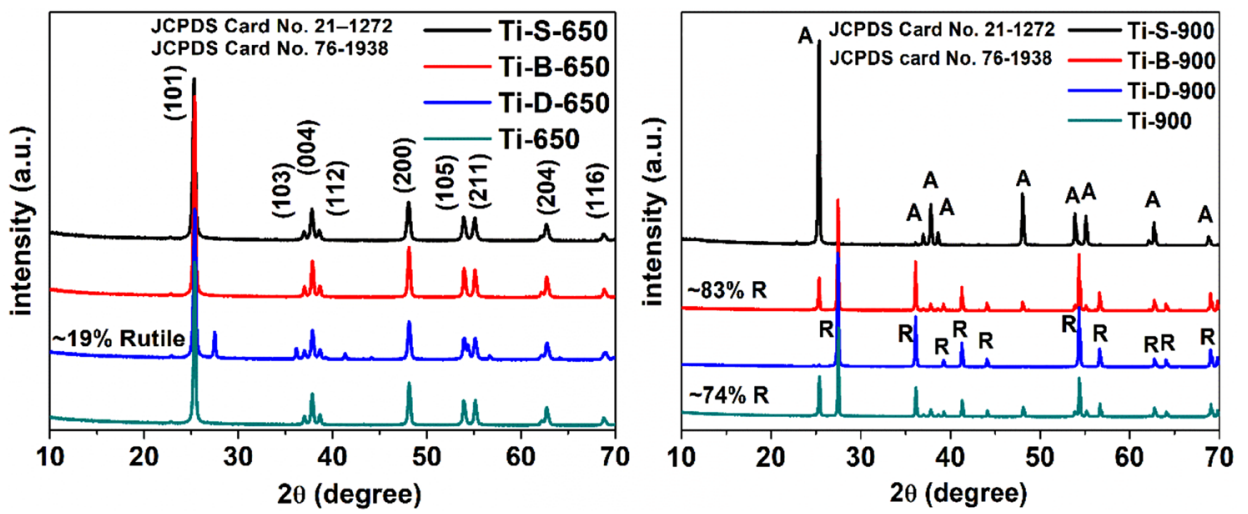

\begin{tabular}{|c|c|c|c|c|c|c|c|c|c|}
\hline \multirow[t]{2}{*}{ Sample name } & \multicolumn{6}{|c|}{ Lattice parameters } & \multicolumn{3}{|c|}{ Crystallite size $(\mathrm{nm})$} \\
\hline & $a=b(\AA ̊)$ & $c(\AA)$ & Cell volume $\left(\AA^{3}\right)$ & $R_{p}$ & $\mathrm{R}_{\mathrm{wp}}$ & $\chi^{2}$ & $500^{\circ} \mathrm{C}$ & $650^{\circ} \mathrm{C}$ & $900^{\circ} \mathrm{C}$ \\
\hline Ti-S-500 & 3.7859 & 9.4932 & 136.06 & 6.30 & 6.30 & 6.30 & 10.3 & 28.9 & 66.6 \\
\hline Ti-B-500 & 3.7797 & 9.4716 & 135.31 & 7.92 & 7.30 & 5.6 & 8.0 & 37.3 & 71.3 \\
\hline Ti-D-500 & 3.7875 & 9.5159 & 136.50 & 6.80 & 6.81 & 7.7 & 10.3 & 32.8 & - \\
\hline Ti-500 & 3.7900 & 9.4939 & 136.36 & 8.59 & 9.47 & 7.2 & 10.6 & 38.7 & 64.9 \\
\hline
\end{tabular}

$A_{1 g}$ mode is the result of asymmetric bending vibration of O-Ti-O. From the Raman spectra, broadening and shifting of Raman active modes (to higher wavenumber) are observed for Ti-B-500 nanoparticles, which is due to the lower crystallite size of the nanoparticles. Change in crystallites size (to lower value) changes the vibrational properties of the Ti-B-500 nanoparticles. Owing to the size-induced radial pressure, a volume contraction occurs 


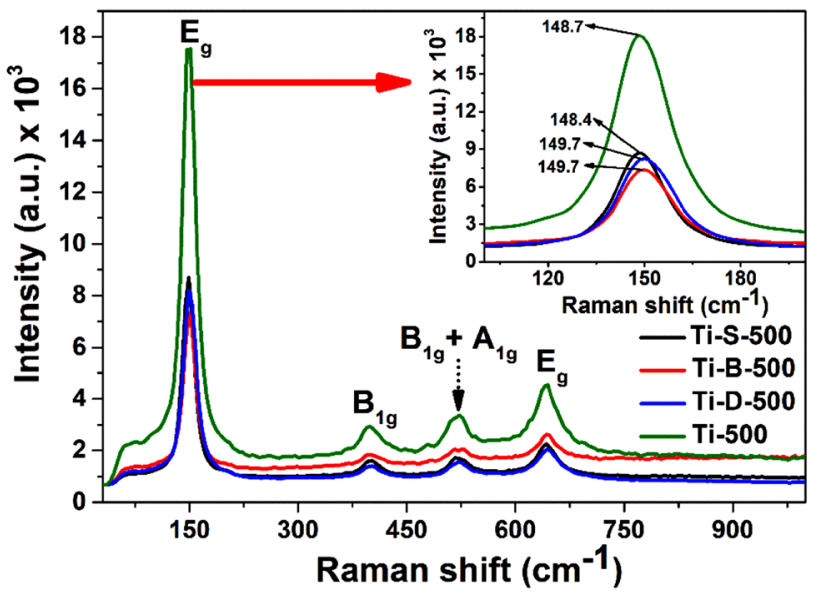

Fig. 2 Raman shifts pattern in Ti-(S, B and D)-500 nanoparticles
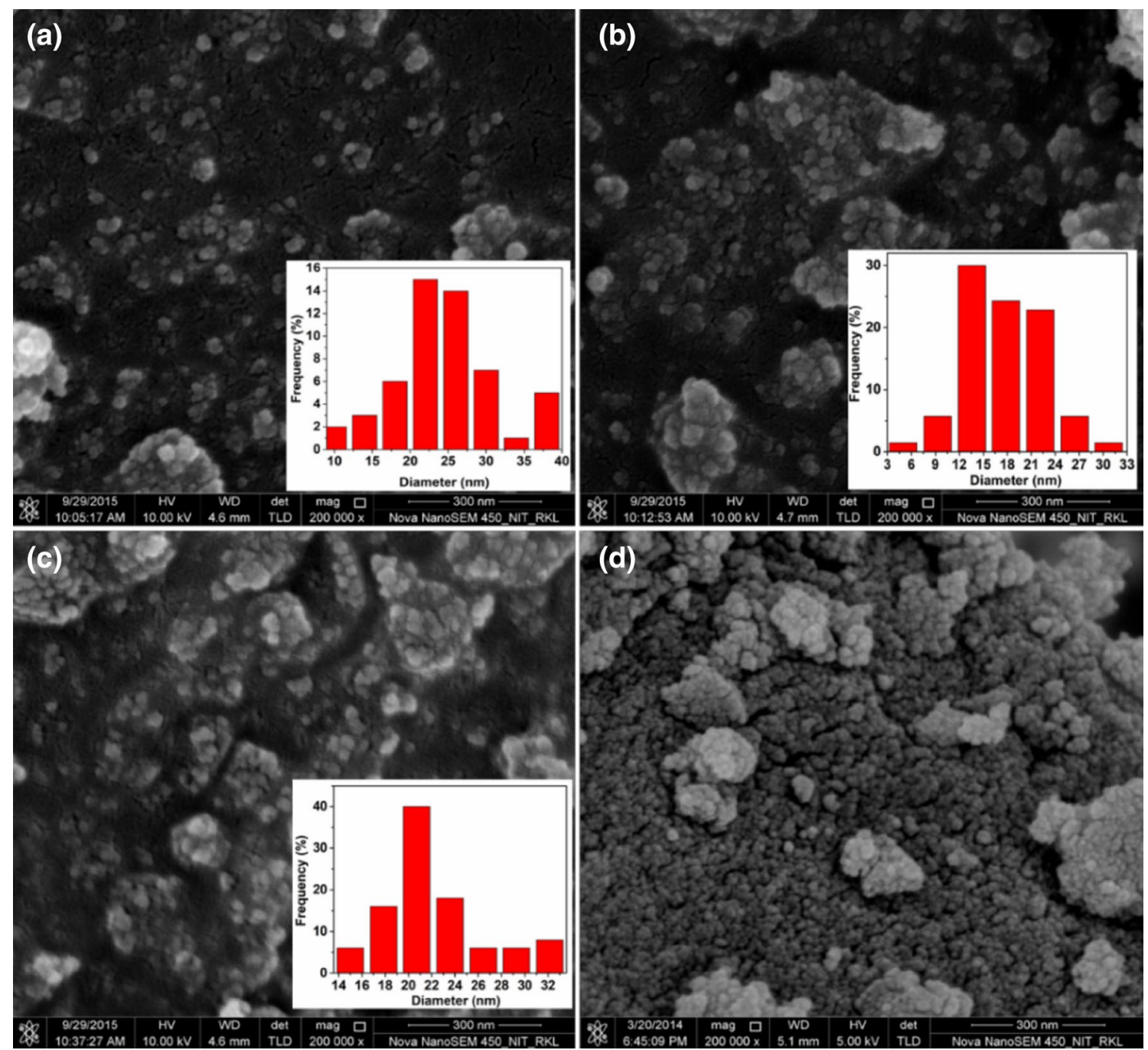

Fig. 3 FESEM Micrographs of a Ti-S-500, b Ti-B-500 c Ti-D-500 and d Ti-500 nanoparticles 
and Ti-D-500 have average particle size of 24.4, 17.5, and $22.2 \mathrm{~nm}$ respectively. It was very difficult to calculate the particle size for Ti-500 due to its agglomerated nature.

The nanoparticles are also observed by the high resolution transmission electron microscope (HRTEM) to identify the nucleation nature of nanoparticles. Ti-S-500 nanoparticles shown in Fig. 4a are found to be weakly agglomerated, and of uniform in size. Figure 4a.1 displays the lattice fringes corresponding to the anatase phase with inter-planar (101) distance of $0.364 \mathrm{~nm}$. The stable regular and worm-like pores formed in Ti-B-500 nanoparticles are shown in Fig. 4b.3. Development of anatase nanocrystals confirmed from the formation of lattice fringes with an inter-planar (101) distance of $0.357 \mathrm{~nm}$ is shown in
Fig. 4b.1. Figure $4 \mathrm{c}$ shows the non-porous microstructure of Ti-D-500 nanoparticles with a geometrical shape and the particles have an anatase phase with inter-planar (101) distance of $0.364 \mathrm{~nm}$. Figure $4 \mathrm{~d}$ shows the agglomerated nanoparticles of Ti-500, formed via the growth of bigger particles after nucleation as there is an absence of surfactant throughout the synthetic process. The particles have anatase phase with inter-planar (101) distance of $0.359 \mathrm{~nm}$. The ring pattern observed in selected area electron diffraction (SAED) pattern in Fig. 4a.2, b.2, c.2 and d. 2 indicates the development of well crystalline nature in all nanoparticles.

In order to understand the nucleation process of titania nanoparticles, we have proposed a mechanistic
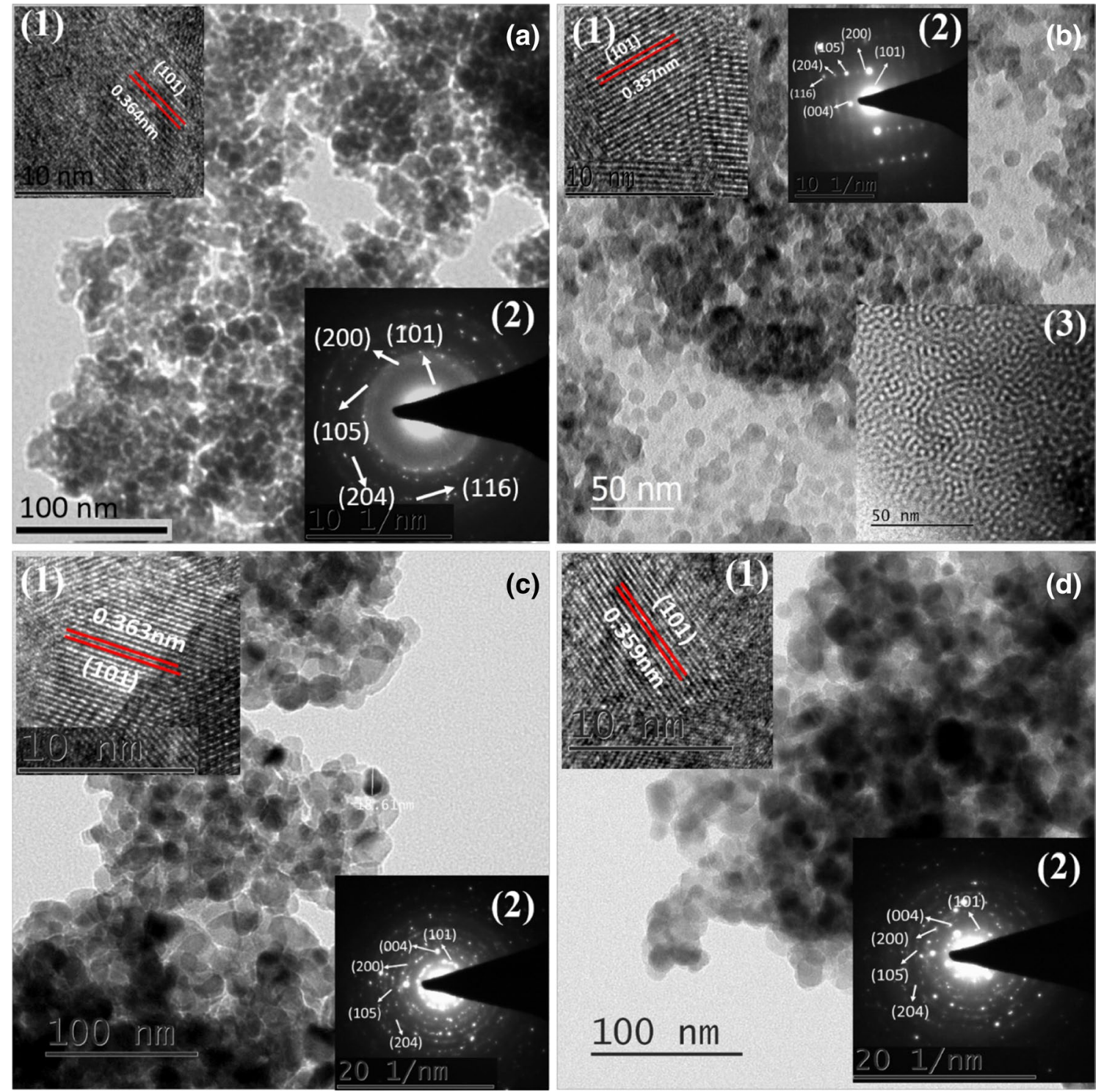

Fig. 4 TEM Micrographs, HRTEM micrographs (inset), and SEAD pattern (inset) of a Ti-S-500, b Ti-B-500 c Ti-D-500 and d Ti-500 nanoparticles

SN Applied Sciences

A SPRINGER NATURE journal 
pathway about how the particles are designed according to their microstructure. Due to the ionic nature of SDS and DDA, they are dissolved in water and also they started to form micelle in solution at CMC. The surfactant head groups (polar groups) of the micelles attracted first the precursor ions $\left(\mathrm{Ti}^{4+}\right)$ and then the precipitating agent that was introduced. As the surfactants are polar in nature, they are organized in solution to form a unilameller vesicle in which, both the precursor and precipitating agent are present. After that, they formed the corresponding precipitate $\left(\mathrm{TiO}(\mathrm{OH})_{2}\right)$ into the core of the vesicle. During the ageing process, the precipitate gets aggregated into core and while washing the precipitate, the excess surfactant from the solution gets removed. When the precipitate is annealed at $500^{\circ} \mathrm{C}$, the corresponding oxide $\left(\mathrm{TiO}_{2}\right)$ is formed with a geometrical shape due to the complete removal of the surfactant. The nucleation of the nanoparticles is illustrated in Fig. $5 \mathrm{a}$. When the non-ionic (Brij C10) nature of the surfactant prevails, strong interaction between the solvent and surfactant does not operate. As a result, the surfactant molecules get self-aggregated in different shapes in the solution as shown in Fig. 5 biii and the precipitate forms without any core, whereas the ionic surfactants does it. After ageing and washing, the precipitate is annealed at $500{ }^{\circ} \mathrm{C}$, which removes the surfactant from the samples generating a pore within the resultant oxide.

\subsection{BET surface area and pore size distribution}

Figure 6a shows the nitrogen adsorption-desorption isotherms of nanoparticles. All the nanoparticles show type IV isotherm with a hysteresis loop, but the isotherm of Ti-B-500 is the vibrant one which confirms the presence of mesopores [53]. Specific surface area, pore diameter and total pore volume of the nanoparticles are listed in Table 2. Ti-B-500 nanoparticles have a higher surface area of $117 \mathrm{~m}^{2} / \mathrm{g}$ compared to others due to the formation of pores [also confirmed in TEM micrographs (Fig. 4b.3)]. The structural properties, surface area, and pore volume indicate that the Brij $\mathrm{C} 10$ surfactant assisted $\mathrm{TiO}_{2}$ has a technologically advanced anatase nanostructure. Figure $6 \mathrm{~b}$ illustrates the pore-size distribution plot of the corresponding nanoparticles. A sharp peak appeared approximately at $8 \mathrm{~nm}$ for Ti-B-500 and it is gradually decreased to $55 \mathrm{~nm}$ indicating the availability of large amount of mesopores along with some macropores (55-150 nm). Ti-500 nanoparticles also have a sharp peak like Ti-B-500 indicating the formation of pores, but it has not been found in TEM, which suggest that it may appear due to the formation of grain boundaries.

\subsection{XPS analysis}

X-ray photoelectron spectroscopy (XPS) has been carried out to understand the elemental identification and chemical states of element present in the titania nanoparticles. Figure 7 displays the XPS survey spectra, high-resolution spectra of Ti $2 p$ and $O 1 s$ and the binding energy (BE) values along with atomic percentage of the elements. Survey spectrum confirmed the presence of $\mathrm{Ti}, \mathrm{O}$, and $\mathrm{C}$ atoms in all the nanoparticles. The carbon peak is attributed to adventitious hydrocarbon from XPS instrument itself. Additionally, the Ti-B-500 nanoparticles contain $\mathrm{N}$-atom (1.32 at.\%) and S-atom (1.57 at.\%) as evident from the survey spectrum. The high-resolution spectra of Ti $2 p$ of Ti-B500 represent the binding energies of Ti $2 p_{3 / 2}$ and Ti $2 p_{1 / 2}$, which are centered at $457.3 \mathrm{eV}$ and $462.3 \mathrm{eV}$ respectively, corresponding to a spin-orbit coupling. The high-resolution $\mathrm{O} 1 \mathrm{~s}$ peak could be deconvoluted into two peaks at $528.1 \mathrm{eV}$ and $530.1 \mathrm{eV}$, corresponding to Ti-O-Ti and $\mathrm{Ti}-\mathrm{O}-\mathrm{H}$ bonds, respectively. According to the previous literature, pure $\mathrm{TiO}_{2}$ has binding energies of $\mathrm{Ti} 2 \mathrm{p}_{3 / 2}$ and $\mathrm{Ti}$ $2 p_{1 / 2}$ at $459.0 \mathrm{eV}$ and $464.7 \mathrm{eV}$ respectively [54]. Here, the pure Ti-500 nanoparticles have binding energies of Ti $2 p_{3 / 2}$ and Ti $2 p_{1 / 2}$ at $458.9 \mathrm{eV}$ and $464.9 \mathrm{eV}$ respectively. Therefore, the lower shifts in binding energy of Ti-B-500 nanoparticle are due to the presence of mixed $\mathrm{O}-\mathrm{S}$ atom into the lattice environment which is confirmed by National Institute of Standards and Technology (NIST) XPS database [55]. Binding energies of Ti $2 p$ (Ti $2 p 3_{/ 2}$ and Ti $2 p_{1 / 2}$ states) and $\mathrm{O} 1 \mathrm{~s}$ (deconvoluted peaks corresponding to $\mathrm{Ti}-\mathrm{O}-\mathrm{Ti}$ and $\mathrm{Ti}-\mathrm{O}-\mathrm{H}$ bonds) in other nanoparticles are indicated to their corresponding high-resolution spectra. The source of sulphur in Ti-B-500 nanoparticles is from the precursor $\left(\mathrm{TiOSO}_{4}\right)$. To make the precipitates sulphate free, each time the filtered solutions are cross checked with $\mathrm{BaCl}_{2}$ test. However, during synthesis of Ti-B-500, some sulphate ions remained with the surfactant Brij C10. Due to non-ionic nature of the surfactant, complete removal does not take place and after calcination, sulphur atoms are introduced to Ti-B-500 nanoparticles.

\subsection{Band gap measurement}

The optical responses of the nanoparticles are investigated using UV-DRS as shown in Fig. 8a. The Ti-B-500 nanoparticles show an absorption edge around $416 \mathrm{~nm}$ and the other nanoparticles are closer to $395 \mathrm{~nm}$, i.e. a red shift. The red shift may be attributed to the presence of sulphur atom in the lattice. Both $\mathrm{Ti} 3 \mathrm{~d}$ and $\mathrm{O} 2 \mathrm{p}$ orbitals in pure $\mathrm{TiO}_{2}$ are the participant of the valence band (VB) and conduction band (CB). Splitting of the Ti $3 d$ orbital (VB) generates two parts: the $t_{2 g}$ and $e_{g}$ states and CB divided into the lower and upper parts. Presence of sulphur (the $S 3 p$ 
Fig. 5 A plausible mechanistic pathway to the formation of a Ti-S-500, Ti-D-500 and b Ti-B500 nanoparticles (a)

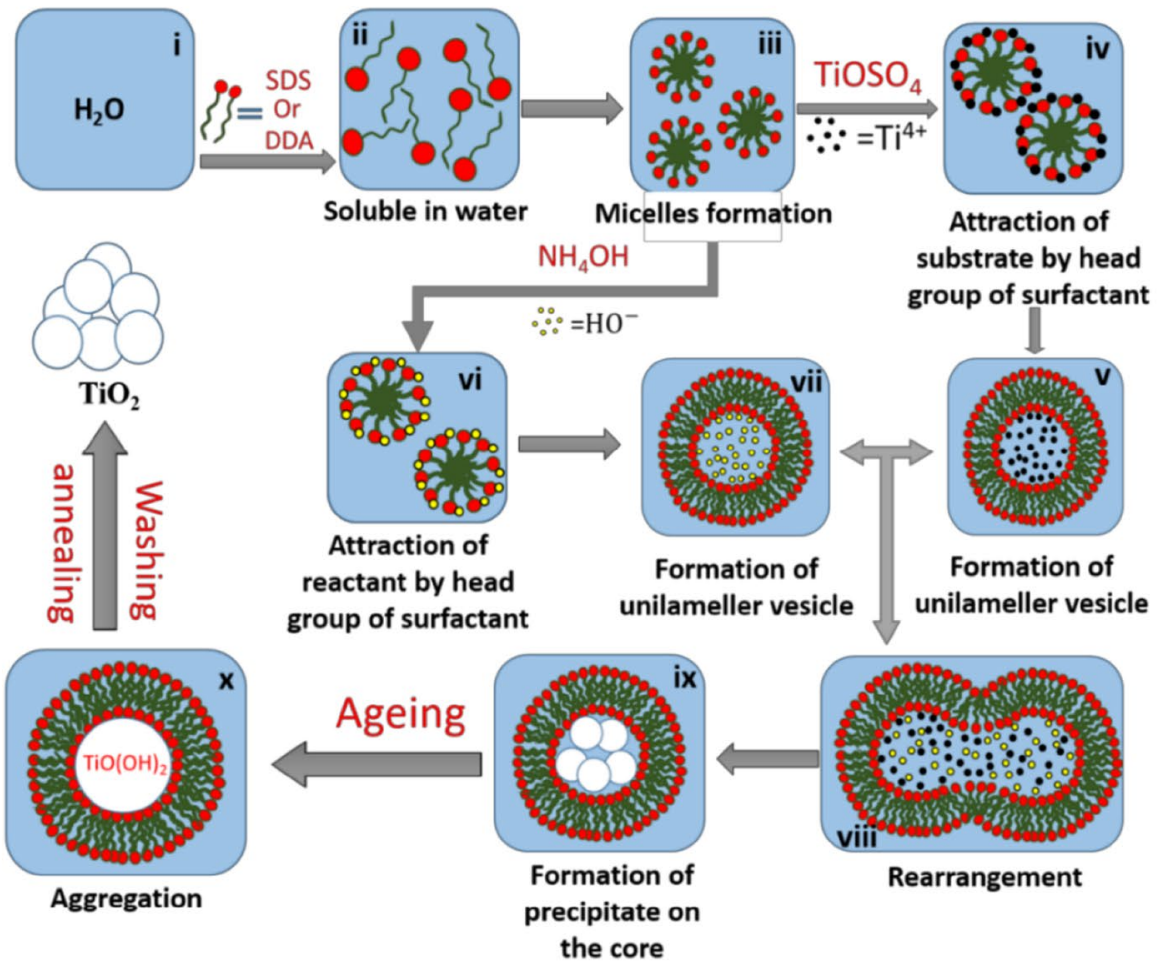

(b)
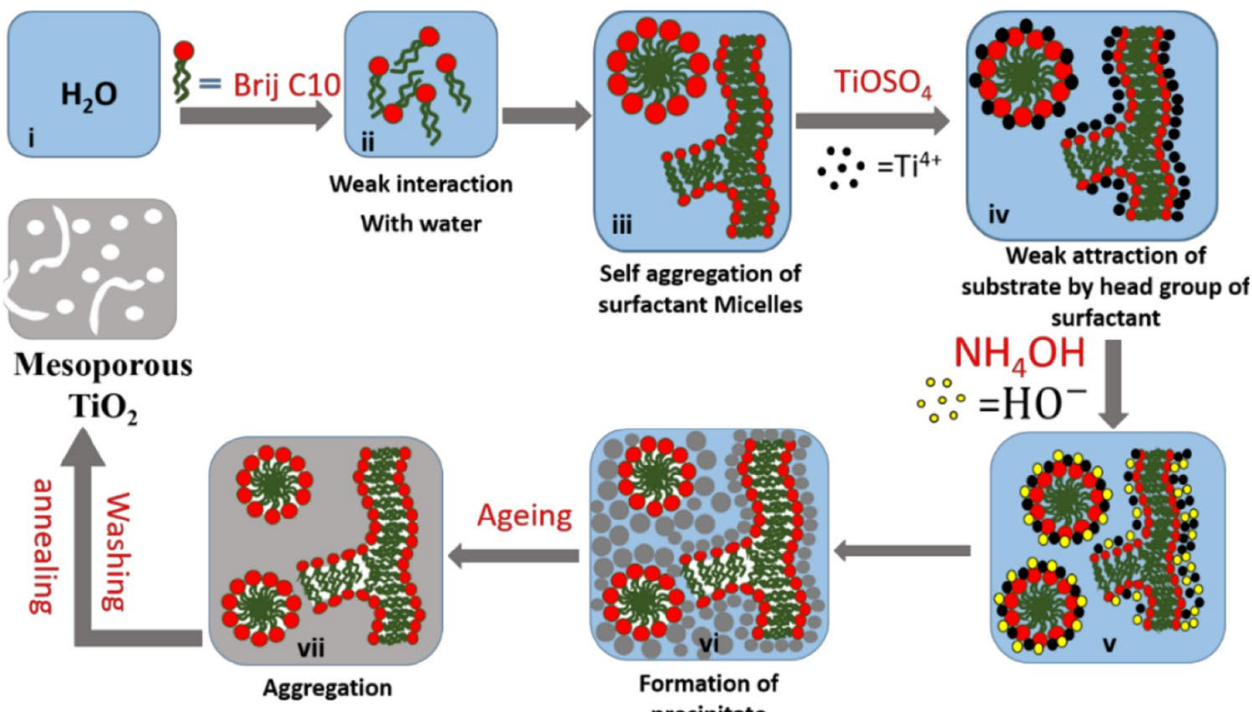

$\mathrm{NH}_{4} \mathrm{OH}$ $\therefore=\mathrm{HO}^{-}$

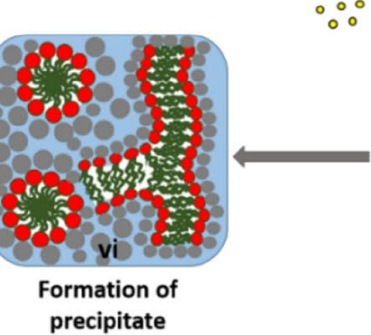

states) in the lattice may be contributing to the formation of $V B$ with the $O 2 p$ and $T i 3 d$ states because some extents of the $S 3 p$ state is delocalized. Thus, the mixing of $S 3 p$ states with VB increases the width of the VB itself [56]. This result arises in the red shift and consequently decreases the band gap energy in Ti-B-500 nanoparticles. The direct and indirect band gap energies are calculated using Tauc's plot and marked in the inset of Fig. $8 \mathrm{~b}$ and c, respectively.

\subsection{CIS analysis}

The complex impedance spectroscopy (CIS) is a powerful and sensitive characterization technique to investigative the electron-transfer kinetics occurring in different materials, like single crystal, polycrystalline, polymer composite and amorphous ceramics over a wide range of temperatures. Moreover, a relationship between electrical and microstructural properties can be established 
(a)

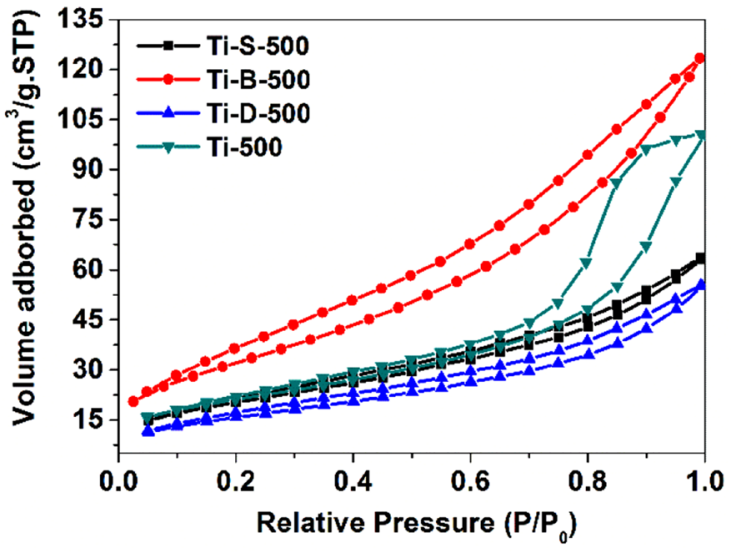

(b)

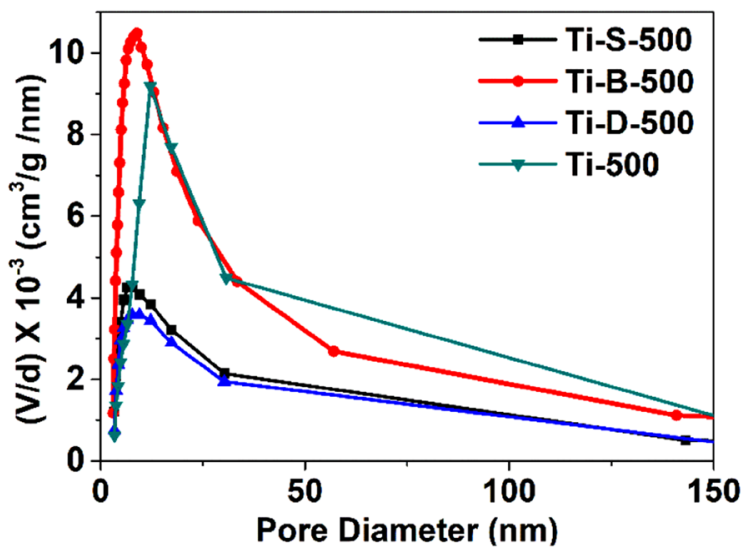

Fig. 6 a $\mathrm{N}_{2}$ adsorption-desorption isotherms and $\mathbf{b}$ pore size distribution plot of Ti-(S, B and D)-500 nanoparticles

Table 2 Surface area, pore diameter and pore volume of Ti-(S, B and D)-500 nanoparticles

\begin{tabular}{lcccc}
\hline Sample name & Ti-S-500 & Ti-B-500 & Ti-D-500 & Ti-500 \\
\hline Surface area $\left(\mathbf{m}^{\mathbf{2}} \mathbf{g} \mathbf{g}\right)$ & 72.3 & 117.4 & 57.2 & 74.4 \\
Pore diameter $(\mathbf{n m})$ & 3.41 & 3.29 & 3.82 & 12.2 \\
$\begin{array}{c}\text { Total pore volume } \\
\left(\mathbf{c m}^{\mathbf{3}} \mathbf{g}^{-1}\right)\end{array}$ & 0.098 & 0.190 & 0.085 & 0.156 \\
\hline
\end{tabular}

i.e., the electrical properties of a polycrystalline ceramic depend on its grains, grain boundary and space charge polarization. The electric relaxation process occurring at the microscopic dimensions can be visualized using equivalent circuits to elucidate the experimentally perceived impedance spectra. Resistance (R), capacitance $(C)$, inductance $(\mathrm{L})$ and constant phase elements $(\mathrm{Q})$ are the essentials of an equivalent circuit. These elements are linked in series and/or parallel to describe the relaxation phenomena occurring due to the grains, grain boundary and space charge polarization. The fundamental complex electrical parameters (like admittance $\left(Y^{*}\right)$, permittivity $\left(\varepsilon^{*}\right)$, impedance $\left(Z^{*}\right)$, and electric modulus $\left(M^{*}\right)$ ) obtained from CIS technique are interlinked to each other $[57,58]$. The relations between the parameters are expressed as;

$$
\begin{aligned}
& \text { Complex impedance }\left(Z^{*}\right)=Z^{\prime}-i Z^{\prime \prime} \\
& \text { Complex admittance }\left(Y^{*}\right)=Y^{\prime}+i Y^{\prime \prime}=1 / Z^{*} \\
& \text { Complex permittivity }\left(\varepsilon^{*}\right)=\varepsilon^{\prime}-i \varepsilon^{\prime \prime}=1 / 1 \omega C_{o} Z^{*} \\
& \text { Complex modulus }\left(M^{*}\right)=M^{\prime}+i M^{\prime \prime}=i \omega C_{o} Z^{*}
\end{aligned}
$$

where single prime ('), double prime ("), i, $C_{\mathrm{o}}$ and $\omega$ represent the real part, imaginary part, imaginary factor $(\sqrt{ }-1)$,

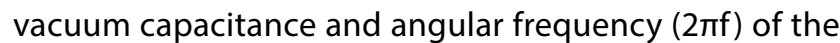
complex electrical parameters, respectively.

Figure 9a shows the room temperature impedance spectra of the titania nanoparticles. The Nyquist plots are modeled using RQ-RQ circuit and are represented in Fig. 9b. All the samples show formation of two semicircular arcs. The arc at high frequency (1st) is due to the grain property while the low frequency arc (2nd) signifies the grain boundary of the samples. The radius of the arcs gives the resistance of individual grain $\left(R_{g}\right)$ and grain boundary $\left(R_{g b}\right)$. It is observed that Ti-S-500 catalyst (Fig. $9 b$ ) has the largest arc radius among the rest. Therefore, it has higher resistance value in both grain and grain boundary. On the other hand, Ti-B-500 displays the low resistance value at grain and grain boundary (i.e., smaller arc radius) due to the porous nature of Ti-B-500 catalyst (Fig. 4b). It is alleged that mesoporous $\mathrm{TiO}_{2}$ is a consequence of the unique character of well-sintered nanograins (at interfaces). Thus, it formed a facile electronic transport path with a long diffusion length as in 1D single crystalline nanorods [59]. Therefore, it is assumed that the enhanced diffusion length for electrons in Ti-B-500 catalyst is because of the formation of accumulation of electrons at the grain-grain interface [60]. Such assembly of electrons at the interface assists electronic conduction across the grains. The resistance values of Ti-D-500 and Ti-500 catalyst are similar and fall between the Ti-B-500 and Ti-S- 500 . The resistance values of the samples are tabulated in Table 3.

As per CIS analysis, it is observed that Ti-B-500 catalyst has low resistance at both grain and grain boundary, which indicates high charge transfer rate (i.e. larger electron-hole separation). The increased electron-hole separation rate leads to the formation of effective active site to participate in reaction at surface of the catalyst, which 

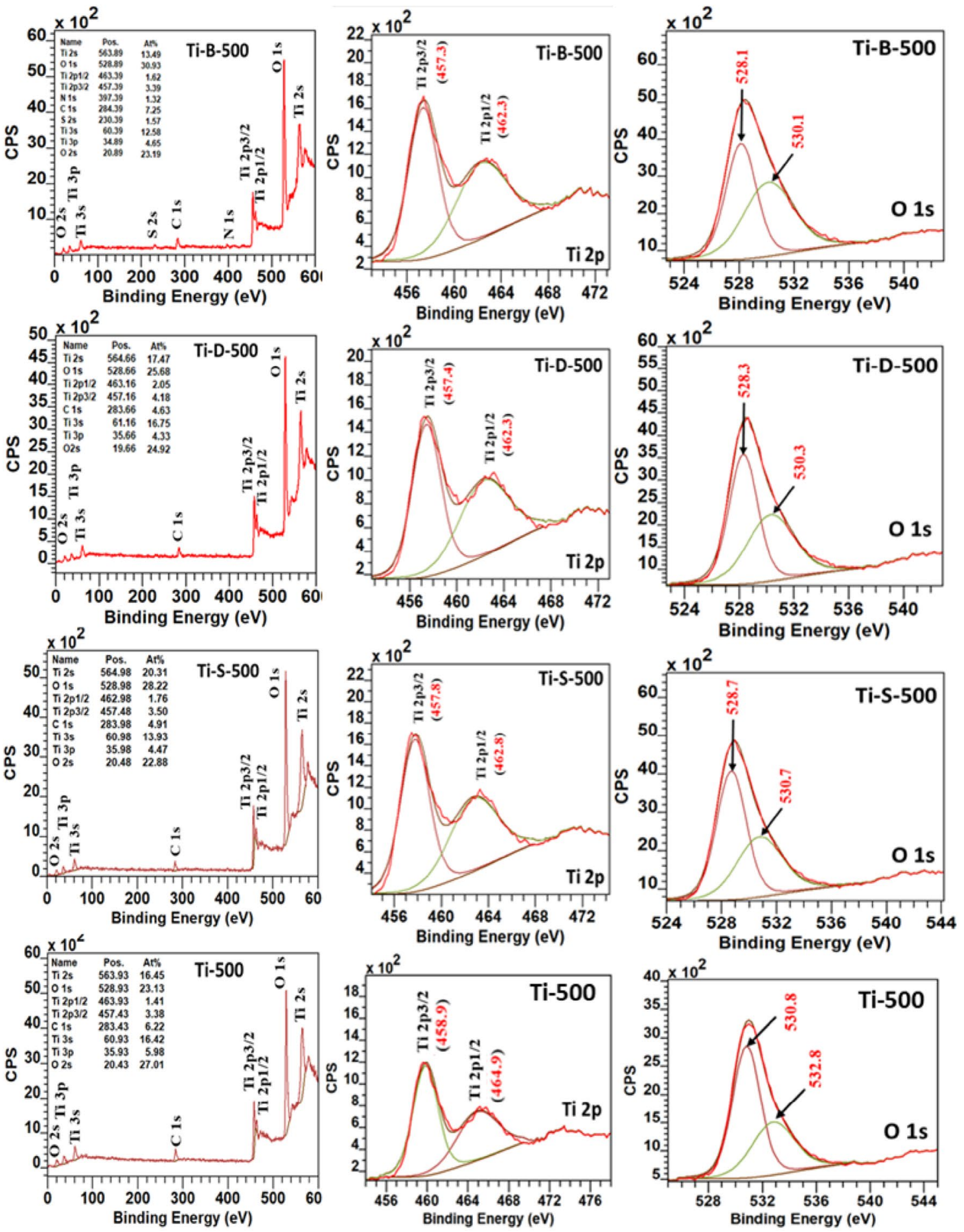

Fig. 7 XPS full survey spectrum and high-resolution spectra of Ti $2 p$ and $\mathrm{O} 1 \mathrm{~s}$ in Ti-(S, B and D)-500 nanoparticles 
(a)
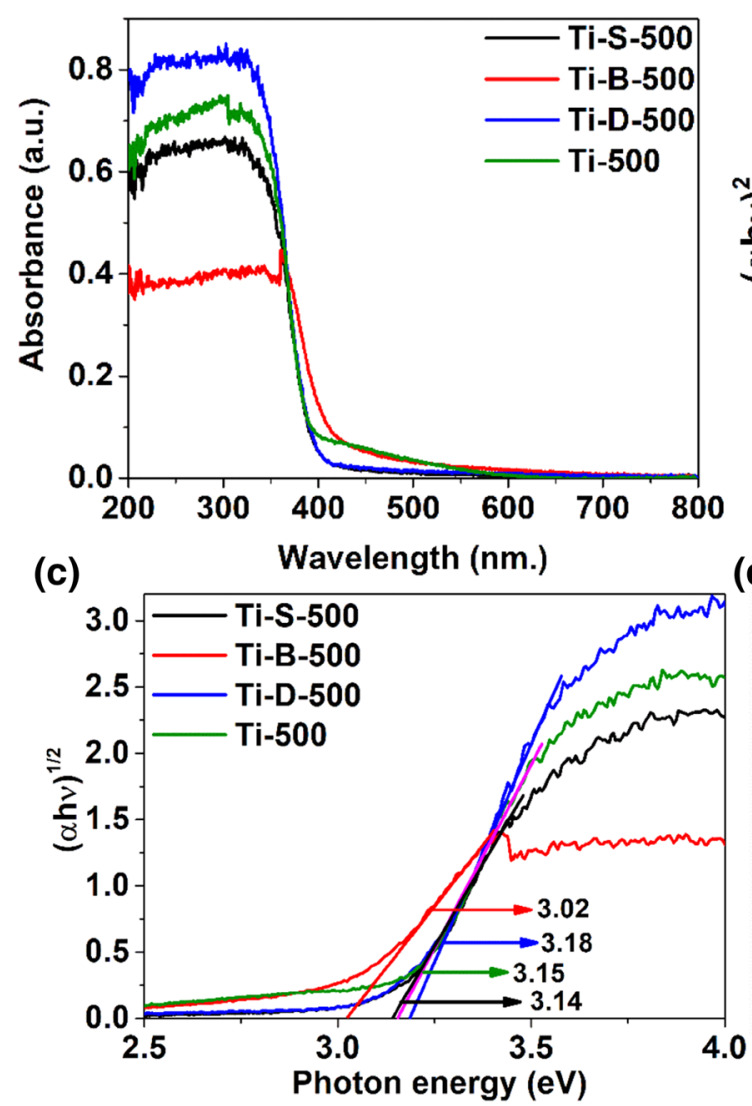

(b)

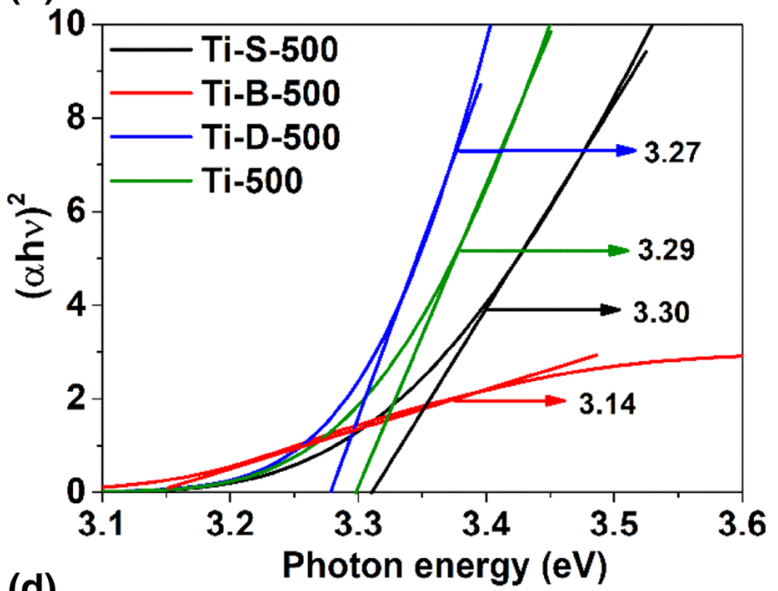

(d)

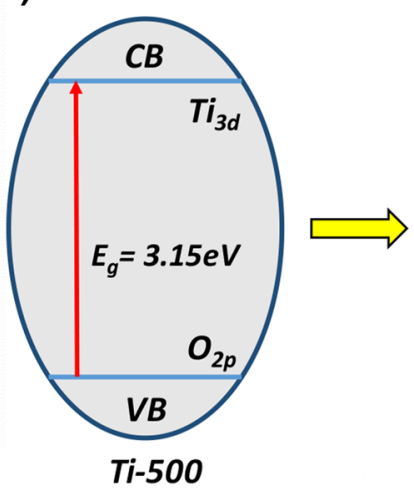

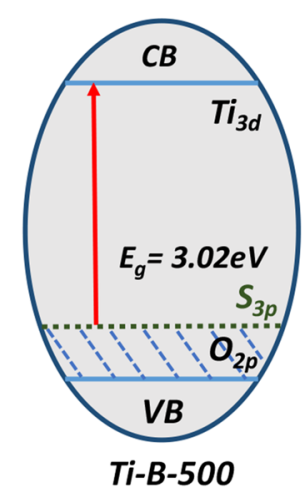

Fig. 8 a UV-vis absorption spectra, $\mathbf{b}$ direct band gap, $\mathbf{c}$ indirect band gap and $\mathbf{d}$ the schematic diagram of S 3p modified VB of Ti-(S, B and D)-500 nanoparticles

shows the enhanced photocatalytic activity in Ti-B-500 catalyst.

\section{Photocatalytic application}

\subsection{Effect of contact time}

The photocatalytic activity of the nanoparticles is evaluated in terms of degradation efficiency. Before the photocatalytic experiment, dye adsorption on the respective nanoparticles is examined. The maximum adsorption about $11 \%$ is observed for Ti-D-500 nanoparticles during the adsorption-desorption equilibrium. Ti-B-500 nanoparticles showed a maximum of $93 \%$ degradation within 30 min under sunlight. The complete degradation of $\mathrm{MB}$ using Ti-B-500 is observed after 60 min of sunlight irradiation. Figure 10a displays the percentage of degradation of MB dye at different time interval of the respective nanoparticles. Percentages of photodegradation by Ti-S-500, Ti-D-500, and Ti-500 nanoparticles are observed about 44\%, 37\%, and $27 \%$ respectively. The photocatalytic reactions follow the first order rate kinetics (Fig. 10b). According to the first order rate kinetics, the rate constant $(k)$ can be calculated using the equation $\ln \left(C_{t} / C_{0}\right)=k t$, where, $C_{t}$ and $C_{0}$ are the concentrations at " $t$ " time and initial concentration, respectively. The kinetic rate has been calculated and summarized in Table 4, which indicates the photodegradation rate for Ti-B-500 is 4.5, 2.3, and 1.4 times higher than the Ti-500, Ti-S-500, and Ti-D-500 respectively. The rate of MB photocatalytic degradation is found to be comparable to the literature data. Zhang et al. reported MB $\left(1 \times 10^{-5}(\mathrm{M})\right)$ photocatalytic degradation under visible light (Xe lamp $(500 \mathrm{~W})$ ) by $\mathrm{Au} / \mathrm{TiO}_{2}-\mathrm{HAP}-300$ nanocatalyst with rate constant of $0.0955 \mathrm{~min}^{-1}$ [61]. The rate constant of Ti-B-500 and Au/ $\mathrm{TiO}_{2}-\mathrm{HAP}-300$ are comparable but the concentration of $\mathrm{MB}$ is doubled in our case. Pandey et al. reported $\mathrm{ZrC}$ nanoparticles which shows $80 \%$ photodegradation of methylene blue in $5 \mathrm{~h}$ under solar light irradiation with kinetic rate of $0.005 \mathrm{~min}^{-1}$ [62]. Mallakpour et al. synthesized LDH-VB9-TiO ${ }_{2}$ and LDH-VB9-TiO ${ }_{2}$ /cross-linked PVA nanocomposite via facile and green technique and 
Fig. 9 a Nyquist plots of the complex impedance spectra and $\mathbf{b}$ individual fitted Nyquist plots (green line) of the respective titania catalysts. Additionally, the red and blue arc of the semicircles indicates resistance at high and low frequency, respectively

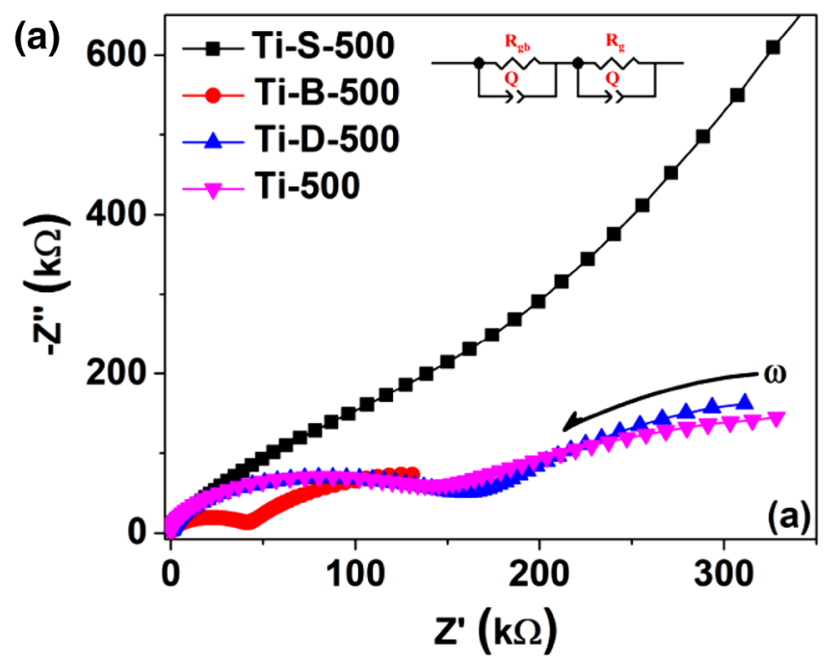

(b)
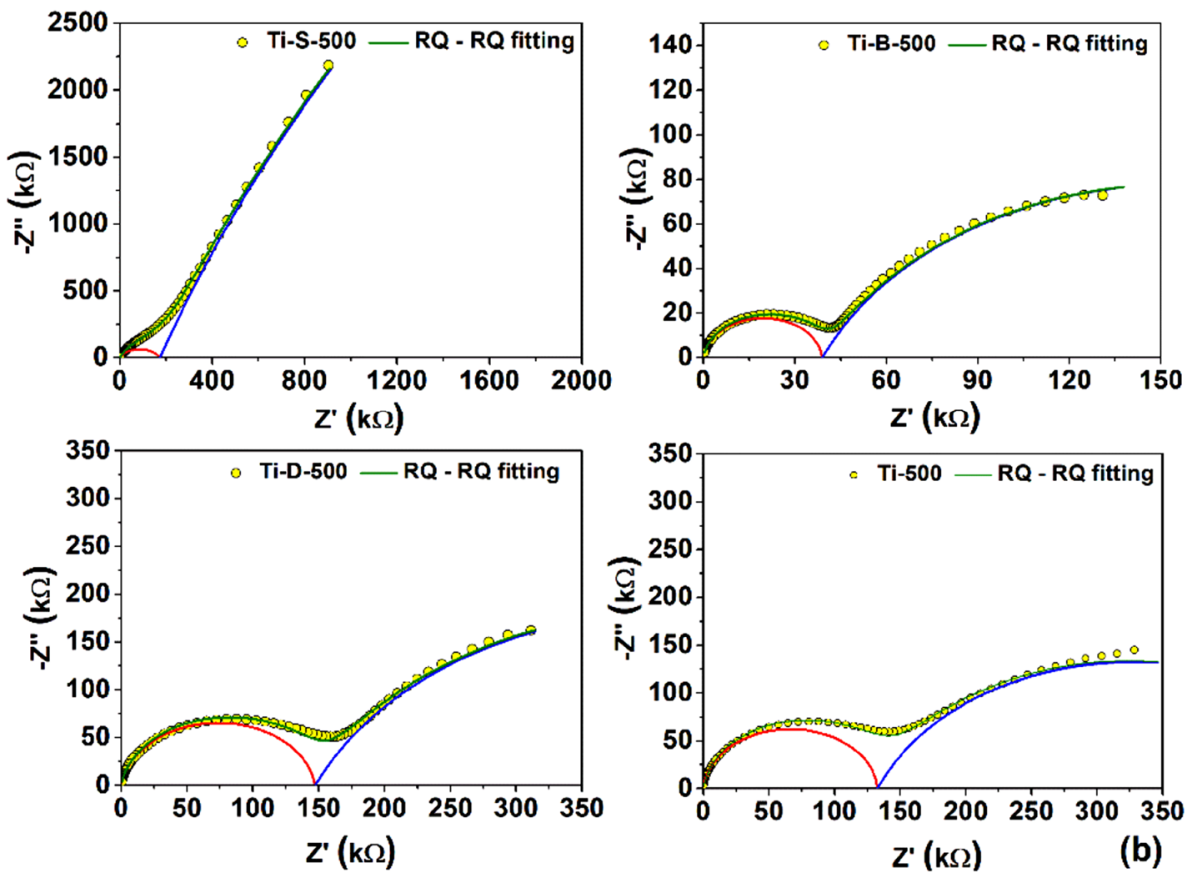

the prepared samples are studied for MB dye degradation under UV-light irradiation. The rate constants are found to be $0.0085 \mathrm{~min}^{-1}$ and $0.0038 \mathrm{~min}^{-1}$ for LDHVB9-TiO ${ }_{2}$ and $\mathrm{LDH}-\mathrm{VB} 9-\mathrm{TiO}_{2}$ /cross-linked PVA nanocomposite, respectively [63]. Poureteda et al. synthesized

Table 3 Grain and grain boundary resistance values of titania catalysts

\begin{tabular}{|c|c|c|c|c|}
\hline Sample name & Ti-S-500 & Ti-B-500 & Ti-D-500 & Ti-500 \\
\hline Grain resistance $(\mathbf{k} \Omega)$ & 174.4 & 39.01 & 147.26 & 132.79 \\
\hline $\begin{array}{l}\text { Grain boundary resist- } \\
\text { ance }(\mathbf{k} \Omega)\end{array}$ & $28,333.00$ & 235.27 & 550.49 & 388.82 \\
\hline
\end{tabular}

$\mathrm{CeO}_{2}$ nanoparticles and studied photodegradation of MB dye. The kinetics rates are found to be $0.0162 \mathrm{~min}^{-1}$ and $0.0157 \mathrm{~min}^{-1}$ under UV and sunlight irradiation, respectively [64]. Therefore, from the literature data it is clear that the Ti-B-500 catalyst has higher photocatalytic activity. The mechanism of photocatalysis by Ti-B-500 nanoparticles is represented in Fig. 10c.

\subsection{Effect of pH on photocatalysis}

To evaluate the effect of $\mathrm{pH}$, experiments have been carried out with the best photocatalyst Ti-B-500. The concentration of dye and catalyst employed is fixed at $2 \times 10^{-5}(\mathrm{M})$ and $1 \mathrm{~g} / \mathrm{L}$ respectively. The photocatalytic degradation is 
(a)

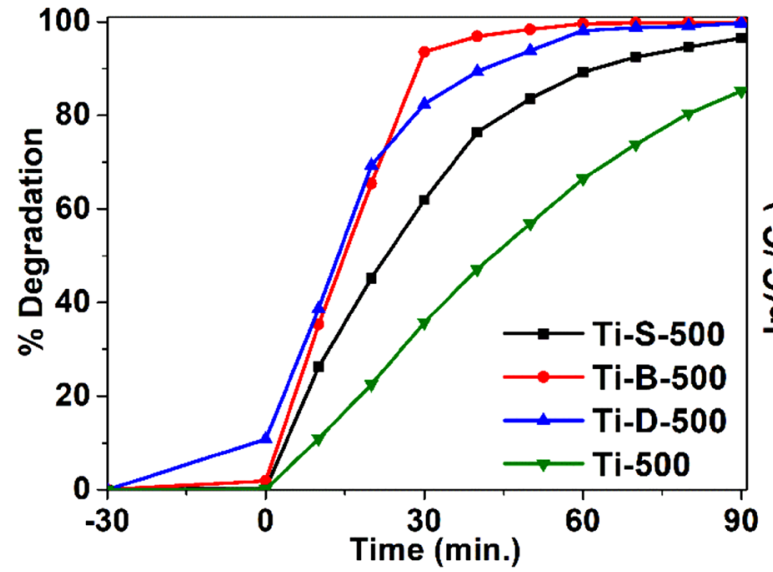

(b)

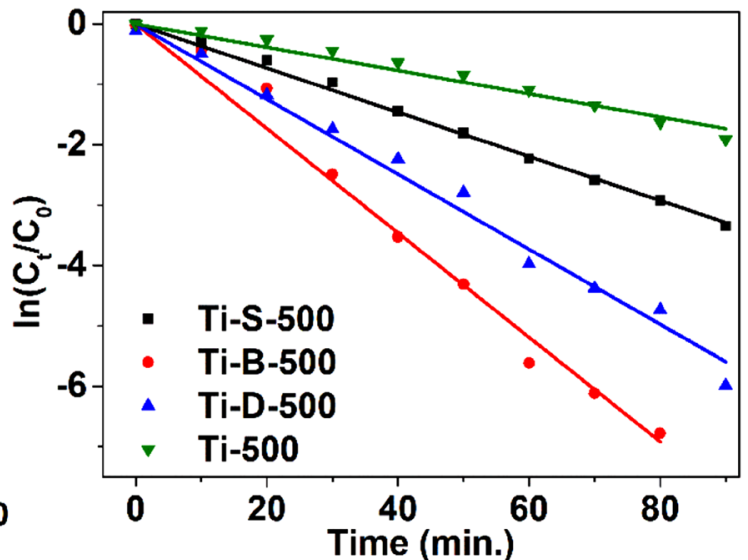

(c) $\mathrm{O}_{2}$

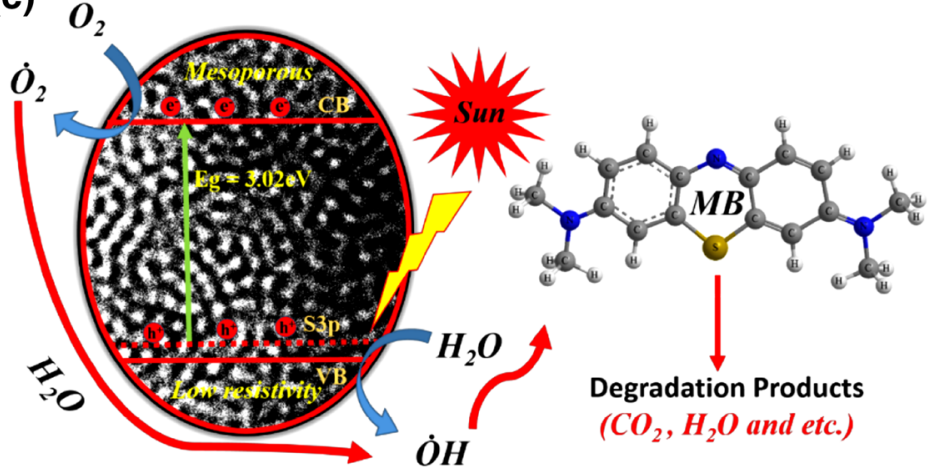

Fig. 10 a Degradation profile at different time interval, b pseudo-first order rate kinetic plot of the MB degradation using titania nanoparticles and $\mathbf{c}$ photodegradation mechanism using Ti-B-500 nanoparticles

Table 4 Pseudo-first order rate kinetic parameters of MB degradation from aqueous solution using Ti-(S, B and D)-500 catalysts

\begin{tabular}{lllll}
\hline Sample name & Ti-S-500 & Ti-B-500 & Ti-D-500 & Ti-500 \\
\hline Rate $\left(\mathbf{m i n}^{-\mathbf{1}}\right)$ & 0.0365 & 0.0864 & 0.0621 & 0.0192 \\
$\mathbf{R}^{\mathbf{2}}$ value & 0.99 & 0.99 & 0.99 & 0.98 \\
\hline
\end{tabular}

performed at $\mathrm{pH}$ of $\sim 3, \sim 5, \sim 9$, and $\sim 11$ at room temperature. Without addition of any acid or base, the $\mathrm{pH}$ of the dye solution has been observed to be 6.7. To adjust the acidic and basic $\mathrm{pH}$ value, $\mathrm{HCl}$ and $\mathrm{NaOH}$ are employed to the dye solutions. The Ti-B-500 nanoparticles noticeably accepted that the photodegradation efficiency on MB and catalysis with $\mathrm{pH}=6.7$ is higher (Fig. 11) compared to the other $\mathrm{pH}$ values which can be ascribed to the surface charge of Ti-B-500 nanoparticles. In the dark environment (during adsorption-desorption equilibrium) there is a slight increase in $\mathrm{MB}$ adsorption at the acidic $\mathrm{pH}$ range but enormous changes in adsorption have been observed at basic $\mathrm{pH}$ range. It is observed that the $\mathrm{MB}$ dye adsorption of $9 \%$ at $\mathrm{pH} \sim 3$ and $12 \%$ at $\mathrm{pH} \sim 5$, whereas $25 \%$ at $\mathrm{pH} \sim 9$

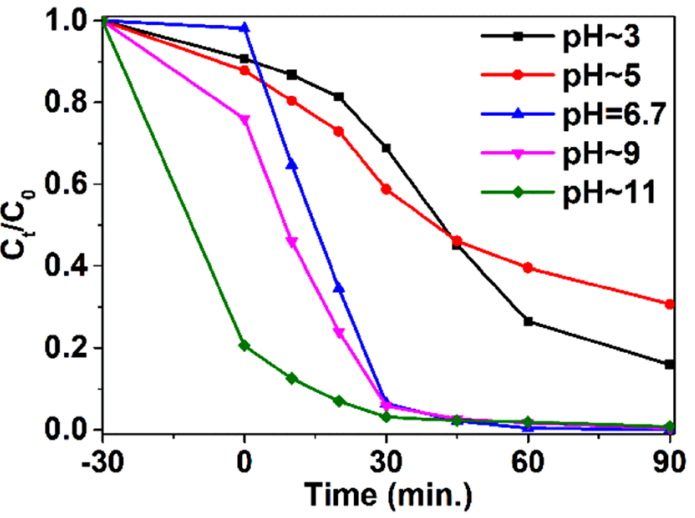

Fig. 11 Effect of pH on photocatalytic degradation using Ti-B-500 catalyst

and $79 \%$ at $\mathrm{pH} \sim 11$. The rate of degradation at various $\mathrm{pH}$ is listed in Table 5. The increase of MB adsorption is due to the negative charge developed on catalyst surface at higher $\mathrm{pH}$. So, a strong electrostatic attraction operates between negatively charge catalyst surface and the MB 
Table 5 Pseudo-first order rate kinetic parameters of photocatalytic degradation at different $\mathrm{pH}$

\begin{tabular}{llllll}
\hline $\mathrm{pH}$ & $\sim 3$ & $\sim 5$ & $=6.7$ & $\sim 9$ & $\sim 11$ \\
\hline Rate $\left(\mathbf{m i n}^{-1}\right)$ & 0.0180 & 0.0124 & 0.0864 & 0.0640 & 0.0410 \\
$\mathbf{R}^{2}$ value & 0.96 & 0.99 & 0.99 & 0.98 & 0.98
\end{tabular}

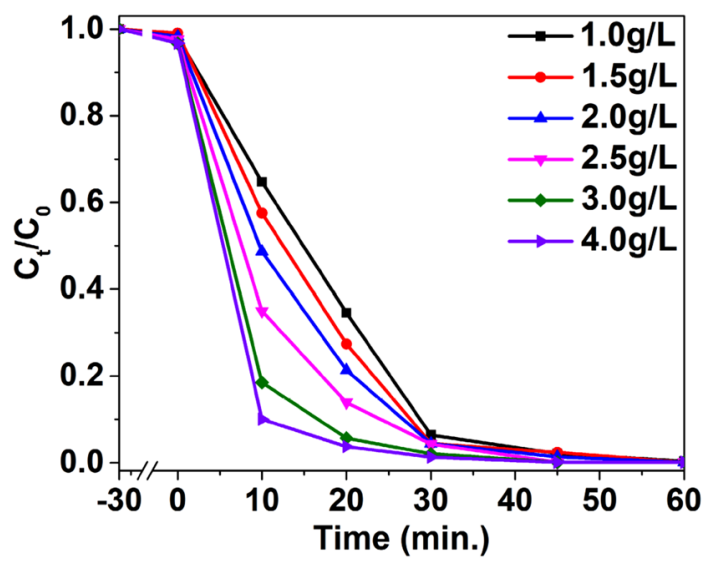

Fig. 12 Effect of catalysts dosage on photocatalytic degradation using Ti-B-500 catalyst

cation [65]. On the other hand, acidic $\mathrm{pH}$ helps to produced more number of holes, which involves in oxidation reaction to enhance the degradation process. However, the study shows that the rate of dye degradation is decreased at acidic $\mathrm{pH}$ because Ti-B-500 nanoparticles may tend to agglomerate and reduce the surface area which is required for maximum dye adsorption as well as photon absorption. In addition, at the high acidic end there operates a repulsive force between the positively charged catalyst surface and the methylene blue cation. On the other hand, hydroxyl radicals $(\mathrm{HO})$ are largely responsible for oxidation process which can be generated in an alkaline solution. So, the catalyst surface becomes negatively charged at $\mathrm{pH} \sim 9$ and strong adsorption occurs with the MB followed by photocatalysis. However, at higher $\mathrm{pH}(\sim 11)$ the dye adsorbed more on the catalyst surface, which subsequently makes the surface less exposed to the sunlight. Therefore, the creation of $\mathrm{HO}^{\prime}$ is reduced, i.e., it makes the oxidation reaction slower and decreases the MB degradation rate.

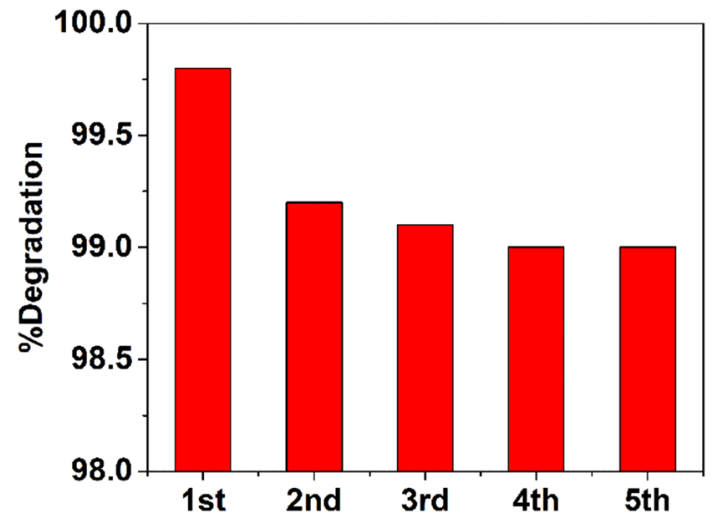

Fig. 13 The recycling ability of Ti-B-500 photocatalyst on MB degradation

\subsection{Effect of catalyst dosage on photocatalysis}

In order to determine the effect of catalyst dosage, the dye degradation process is carried out at best $\mathrm{pH}$ (6.7) with different amount of catalyst dosage ranging from 1.0 to $4.0 \mathrm{~g} / \mathrm{L}$. The kinetic profile is shown in Fig. 12 . The degradation efficiency is found to be increasing fast with the amount of catalyst (Ti-B-500) from 1.0 to $3.0 \mathrm{~g} / \mathrm{L}$. However, it has been found to decrease when the catalyst dosage is increased to $4.0 \mathrm{~g} / \mathrm{L}$. When the catalysts concentration increases, total active surface area increases and resulting in more available active sites on catalyst surface $[66,67]$. This increases the photon adsorption, which promotes the faster rate of photodegradation. Simultaneously, high catalyst dose increases the turbidity of the suspension, which leads to decrease in the penetration of sunlight and hence decreases the volume of photoactivated-suspension [68]. The rates of reaction at different catalyst dosage are calculated and shown in Table 6 . The photodegradation rate increases 1.1 -fold when the dosage varied from 1.0 to $2.0 \mathrm{~g} / \mathrm{L}$ and 1.7 -fold when its $3.0 \mathrm{~g} / \mathrm{L}$. whereas, the rate is only increased 1.9 -fold when the catalyst dosage is $4.0 \mathrm{~g} / \mathrm{L}$.

\subsection{Reusability of the photocatalyst}

In order to find the stability and the reusability of the catalyst, the experiment is carried out for five times, which is believed to provide a significant scope for the real time applications. Each time before the reuse, the photocatalyst
Table 6 Pseudo-first order rate kinetic parameters of $\mathrm{MB}$ photodegradation with the variation of catalyst (Ti-B-500) dosage

\begin{tabular}{lllllll}
\hline Catalyst dosage $(\mathrm{g} / \mathrm{L})$ & 1 & 1.5 & 2 & 2.5 & 3.0 & 4.0 \\
\hline Rate $\left(\mathbf{m i n}^{-1}\right)$ & 0.0804 & 0.0866 & 0.1041 & 0.1218 & 0.1448 & 0.1567 \\
$\mathbf{R}^{\mathbf{2}}$ value & 0.98 & 0.96 & 0.98 & 0.97 & 0.99 & 0.97 \\
\hline
\end{tabular}


has been washed with distilled water and ethanol to remove the dye from its surface and then dried at $60^{\circ} \mathrm{C}$ in an oven. Figure 13 illustrates the reusability profile of the catalyst on photodegradation. After recycling, there are no notable changes observed in the degradation, which evidently indicates that the photocatalyst prepared is reusable and impressively stable enough.

\section{Conclusion}

In this investigation, the authors have reported synthesis and characterization of pure anatase titania nanoparticles using different surfactant templating. Precipitates are formed through controlled hydrolysis method. Structural analysis of XRD patterns has confirmed the formation of pure anatase phase. HRTEM micrographs of Ti-B-500 nanoparticles have manifested the presence of wormlike mesopores structure. Presence of $\mathrm{O}-\mathrm{S}$ mixed environment in the Ti-B-500 lattice is observed to be evident from the XPS study. The presence of sulphur may be reducing the band gap energy and contributing to the photon absorption at visible wavelength. Overall, the Ti-B-500 nanoparticles exhibit an $\mathrm{O}-\mathrm{S}$ mixed environment, high surface area, porosity, smaller particle size, and lower band gap energy. Complex impedance spectra analysis showed effective charge separation in Ti-B-500 catalyst. Methylene blue photodegradation has been carried out under solar light irradiation and Ti-B-500 exhibited high photocatalytic activity with $93 \%$ of degradation. The photocatalysts worked best without any alteration of $\mathrm{pH}$. Optimum dosage of catalysts is in the range $3.0-4.0 \mathrm{~g} / \mathrm{L}$. The photocatalyst exhibited the best photocatalytic activity and high stability after five cycles of experiment. This research can encourage further more investigations on various materials for applications in the fields of photocatalysis of organic pollutants from wastewater.

Acknowledgements The authors are thankful to RRCAT Indore for providing XPS facility. Amar Kundu acknowledges MHRD through NIT Rourkela for his research fellowship.

\section{Compliance with ethical standards}

Conflict of interest On behalf of all authors, the corresponding author states that there is no conflict of interest.

\section{References}

1. Linares N, Silvestre-Albero AM, Serrano E et al (2014) Mesoporous materials for clean energy technologies. Chem Soc Rev 43:7681-7717. https://doi.org/10.1039/c3cs60435g
2. Song Z, Zhan H, Zhou Y (2010) Polyimides: promising energystorage materials. Angew Chemie - Int Ed 49:8444-8448. https ://doi.org/10.1002/anie.201002439

3. Xiang Z, Cao D (2013) Porous covalent-organic materials: synthesis, clean energy application and design. J Mater Chem A 1:2691-2718. https://doi.org/10.1039/c2ta00063f

4. Li SL, Xu Q (2013) Metal-organic frameworks as platforms for clean energy. Energy Environ Sci 6:1656-1683

5. Wang X, Bai L, Liu H et al (2018) A unique disintegration-reassembly route to mesoporous titania nanocrystalline hollow spheres with enhanced photocatalytic activity. Adv Funct Mater 28:1704208. https://doi.org/10.1002/adfm.201704208

6. Kumar SG, Devi LG (2011) Review on modified $\mathrm{TiO}_{2}$ photocatalysis under UV/visible light: selected results and related mechanisms on interfacial charge carrier transfer dynamics. J Phys Chem A 115:13211-13241

7. Zhang Y, Jiang Z, Huang J et al (2015) Erratum: titanate and titania nanostructured materials for environmental and energy applications: a review (RSC Adv. (2015) 5 (79479-79510)). RSC Adv 5:82632

8. Steinmann V, Brandt RE, Buonassisi T (2015) Photovoltaics: noncubic solar cell materials. Nat Photonics 9:355-357

9. Jana A, Hazra M, Datta J (2017) Periodic voltammetry as a successful technique for synthesizing CdSe semiconductor films for photo-electrochemical application. J Solid State Electrochem 21:3083-3091. https://doi.org/10.1007/s10008-017-3656-6

10. $\mathrm{Xu} \mathrm{H}$, Ouyang $\mathrm{S}$, Liu L et al (2014) Recent advances in $\mathrm{TiO}_{2}$-based photocatalysis. J Mater Chem A 2:12642-12661

11. Sfyri G, Kumar CV, Raptis D et al (2015) Study of perovskite solar cells synthesized under ambient conditions and of the performance of small cell modules. Sol Energy Mater Sol Cells 134:60-63. https://doi.org/10.1016/j.solmat.2014.11.034

12. Yao Z, Yan C, Zhang M et al (2014) N-annulated perylene as a coplanar $\pi$-linker alternative to benzene as a low energy-gap, metal-free dye in sensitized solar cells. Adv Energy Mater. https ://doi.org/10.1002/aenm.201400244

13. Portela R, Hernández-Alonso MD (2013) Environmental applications of photocatalysis. Green Energy Technol 71:35-66. https:// doi.org/10.1007/978-1-4471-5061-9_3

14. Yuan R, Guan R, Shen W, Zheng J (2005) Photocatalytic degradation of methylene blue by a combination of $\mathrm{TiO}_{2}$ and activated carbon fibers. J Colloid Interface Sci 282:87-91. https://doi. org/10.1016/j.jcis.2004.08.143

15. Mandal B, Mondal A, Ray SS, Kundu A (2016) Sm doped mesoporous $\mathrm{CeO}_{2}$ nanocrystals: aqueous solution-based surfactant assisted low temperature synthesis, characterization and their improved autocatalytic activity. Dalt Trans 45:1679-1692. https://doi.org/10.1039/c5dt03688g

16. Kundu A, Mondal A (2019) Structural, optical, physio-chemical properties and photodegradation study of methylene blue using pure and iron-doped anatase titania nanoparticles under solar-light irradiation. J Mater Sci: Mater Electron. https://doi. org/10.1007/s10854-018-00596-z

17. Herrmann JM (2012) Titania-based true heterogeneous photocatalysis. Environ Sci Pollut Res 19:3655-3665. https://doi. org/10.1007/s11356-011-0697-8

18. Gonell F, Puga AV, Julián-López B et al (2016) Copper-doped titania photocatalysts for simultaneous reduction of $\mathrm{CO}_{2}$ and production of $\mathrm{H}_{2}$ from aqueous sulfide. Appl Catal B Environ 180:263-270. https://doi.org/10.1016/j.apcatb.2015.06.019

19. Lee $D$, Kanai $Y$ (2012) Role of four-fold coordinated titanium and quantum confinement in $\mathrm{CO}_{2}$ reduction at titania surface. J Am Chem Soc 134:20266-20269. https://doi.org/10.1021/ja309 $871 \mathrm{~m}$

20. Shao GS, Wang FY, Ren TZ et al (2009) Hierarchical mesoporous phosphorus and nitrogen doped titania materials: synthesis, 
characterization and visible-light photocatalytic activity. Appl Catal B Environ 92:61-67. https://doi.org/10.1016/j.apcat b.2009.07.024

21. Adraider Y, Pang YX, Nabhani F et al (2014) Photocatalytic activity of titania coatings synthesised by a combined laser/sol-gel technique. Mater Res Bull 54:54-60. https://doi.org/10.1016/j. materresbull.2014.03.007

22. Wu JM, Zhang TW, Zeng YW et al (2005) Large-scale preparation of ordered titania nanorods with enhanced photocatalytic activity. Langmuir 21:6995-7002. https://doi.org/10.1021/ la0500272

23. Zhu G, Shan Y, Lin T et al (2016) Hydrogenated blue titania with high solar absorption and greatly improved photocatalysis. Nanoscale 8:4705-4712. https://doi.org/10.1039/c5nr07953e

24. Mathis JE, Kidder MK, Li Y et al (2016) Controlled synthesis of mesoporous codoped titania nanoparticles and their photocatalytic activity. Adv Nano Res 4:157-165. https://doi.org/10.12989 /anr.2016.4.3.157

25. Bouzoubaa A, Markovits A, Calatayud M, Minot C (2005) Comparison of the reduction of metal oxide surfaces: $\mathrm{TiO}_{2}$-anatase, $\mathrm{TiO}_{2}$-rutile and $\mathrm{SnO}_{2}$-rutile. Surf Sci 583:107-117. https://doi. org/10.1016/j.susc.2005.03.029

26. Yu J, Low J, Xiao W et al (2014) Enhanced photocatalytic $\mathrm{CO}_{2}$-reduction activity of anatase $\mathrm{TiO}_{2}$ by coexposed 001 and 101 facets. J Am Chem Soc 136:8839-8842. https://doi. org/10.1021/ja5044787

27. Schneider J, Matsuoka M, Takeuchi M et al (2014) Understanding $\mathrm{TiO}_{2}$ photocatalysis: mechanisms and materials. Chem Rev 114:9919-9986

28. Satoh N, Nakashima T, Yamamoto K (2013) Metastability of anatase: size dependent and irreversible anatase-rutile phase transition in atomic-level precise titania. Sci Rep. https://doi. org/10.1038/srep01959

29. Do KK, Kim HT (2002) Synthesis of titanium dioxide nanoparticles using a continuous reaction method. Colloids Surf A Physicochem Eng Asp 207:263-269. https://doi.org/10.1016/S0927 -7757(02)00140-1

30. Do KK, Lee TJ, Kim HT (2003) Optimal conditions for synthesis of $\mathrm{TiO}_{2}$ nanoparticles in semi-batch reactor. Colloids Surf $\mathrm{A}$ Physicochem Eng Asp 224:1-9. https://doi.org/10.1016/S0927 -7757(03)00256-5

31. Liao DL, Liao BQ (2007) Shape, size and photocatalytic activity control of $\mathrm{TiO}_{2}$ nanoparticles with surfactants. J Photochem Photobiol A Chem 187:363-369. https://doi.org/10.1016/j.jphot ochem.2006.11.003

32. Dong W, Pang G, Shi Z et al (2004) Oriented organization of shape-controlled nanocrystalline $\mathrm{TiO}_{2}$. Mater Res Bull 39:433438. https://doi.org/10.1016/j.materresbull.2003.10.012

33. Dinh CT, Nguyen TD, Kleitz F, Do TO (2009) Shape-controlled synthesis of highly crystalline titania nanocrystals. ACS Nano 3:3737-3743. https://doi.org/10.1021/nn900940p

34. Li XL, Peng Q, Yi JX et al (2006) Near monodisperse $\mathrm{TiO}_{2}$ nanoparticles and nanorods. Chem - A Eur J 12:2383-2391. https:// doi.org/10.1002/chem.200500893

35. Allegri M, Bianchi MG, Chiu M et al (2016) Shape-related toxicity of titanium dioxide nanofibres. PLoS ONE. https://doi. org/10.1371/journal.pone.0151365

36. Li Z, Hou B, Xu Y et al (2005) Comparative study of sol-gelhydrothermal and sol-gel synthesis of titania-silica composite nanoparticles. J Solid State Chem 178:1395-1405. https://doi. org/10.1016/j.jssc.2004.12.034

37. Wu M, Long J, Huang A et al (1999) Microemulsion-mediated hydrothermal synthesis and characterization of nanosize rutile and anatase particles. Langmuir 15:8822-8825. https://doi. org/10.1021/la990514f
38. Sadovnikov AA, Baranchikov AE, Zubavichus YV et al (2015) Photocatalytically active fluorinated nano-titania synthesized by microwave-assisted hydrothermal treatment. J Photochem Photobiol A Chem 303-304:36-43. https://doi.org/10.1016/j. jphotochem.2015.01.010

39. Wang XM, Xiao $P(2006)$ Solvothermal synthesis of titania-zirconia composite. J Mater Res 21:355-368. https://doi.org/10.1557/ jmr.2006.0042

40. Singh R, Raman V (2012) Two-dimensional direct numerical simulation of nanoparticle precursor evolution in turbulent flames using detailed chemistry. Chem Eng J 207-208:794-802. https ://doi.org/10.1016/j.cej.2012.07.064

41. Liu WL, Hsieh SH, Chen WJ (2012) Manufacture and characterization of $\mathrm{TiO}_{2}$ nanowires by CVD. In: Advanced materials, ICAMMP 2011. Trans Tech Publications, pp 697-700. https:// doi.org/10.4028/www.scientific.net/AMR.415-417.697

42. Uchikoshi T, Takahashi H, Shirahata N, Sakka Y (2007) Synthesis of titania thin films by cathodic electrolytic deposition. J Ceram Soc Jpn 115:818-820

43. Zhu Y, Li H, Koltypin $Y$ et al (2001) Sonochemical synthesis of titania whiskers and nanotubes. Chem Commun 24:26162617. https://doi.org/10.1039/b108968b

44. Corradi AB, Bondioli F, Focher B et al (2005) Conventional and microwave-hydrothermal synthesis of $\mathrm{TiO}_{2}$ nanopowders. J Am Ceram Soc 88:2639-2641. https://doi.org/10.111 1/j.1551-2916.2005.00474.x

45. Lee JH, Jung KY, Bin PS (1999) Modification of titania particles by ultrasonic spray pyrolysis of colloid. J Mater Sci 34:40894093. https://doi.org/10.1023/A:1004684520087

46. Kartini I, Meredith P, Da Costa JCD, Lu GQ (2004) A novel route to the synthesis of mesoporous titania with full anatase nanocrystalline domains. J Sol-Gel Sci Technol 31:185-189. https://doi.org/10.1023/B:JSST.0000047984.60654.al

47. Ruso JM, Blanco E, Messina PV (2013) Tuning morphology of mesoporous titanium oxides through fluorinated surfactants-based systems. J Porous Mater 20:95-105. https:// doi.org/10.1007/s10934-012-9578-X

48. Sreethawong T, Suzuki Y, Yoshikawa S (2005) Photocatalytic evolution of hydrogen over nanocrystalline mesoporous titania prepared by surfactant-assisted templating sol-gel process. Catal Commun 6:119-124. https://doi.org/10.1016/j. catcom.2004.11.011

49. Yusuf MM, Imai $H$, Hirashima $H$ (2002) Preparation of porous titania film by modified sol-gel method and its application to photocatalyst. J Sol-Gel Sci Technol 25:65-74. https://doi. org/10.1023/A:1016045111857

50. Etacheri V, Seery MK, Hinder SJ, Pillai SC (2011) Oxygen rich titania: a dopant free, high temperature stable, and visiblelight active anatase photocatalyst. Adv Funct Mater 21:37443752. https://doi.org/10.1002/adfm.201100301

51. Ohsaka T, Izumi F, Fujiki Y (1978) Raman spectrum of anatase, $\mathrm{TiO}_{2}$. J Raman Spectrosc 7:321-324. https://doi.org/10.1002/ jrs.1250070606

52. Tian F, Zhang Y, Zhang J, Pan C (2012) Raman spectroscopy: a new approach to measure the percentage of anatase $\mathrm{TiO}_{2}$ exposed (001) facets. J Phys Chem C 116:7515-7519. https:// doi.org/10.1021/jp301256h

53. Xiong $Y$, He D, Jaber R et al (2017) Sulfur-doped cubic mesostructured titania films for use as a solar photocatalyst. J Phys Chem C 121:9929-9937. https://doi.org/10.1021/acs. jpcc.7b01615

54. Saied S, Sullivan J, Choudhury T, Pearce C (1988) A comparison of ion and fast atom beam reduction in $\mathrm{TiO}_{2}$. Vacuum 38:917922. https://doi.org/10.1016/0042-207X(88)90492-7 
55. Gonbeau D, Guimon C, Pfister-Guillouzo G et al (1991) XPS study of thin films of titanium oxysulfides. Surf Sci 254:81-89. https://doi.org/10.1016/0039-6028(91)90640-E

56. Marszewski M, Marszewska J, Pylypenko S, Jaroniec M (2016) Synthesis of porous crystalline doped titania photocatalysts using modified precursor strategy. Chem Mater 28:7878-7888. https://doi.org/10.1021/acs.chemm ater.6b03429

57. Gerhardt R (1994) Impedance and dielectric spectroscopy revisited: distinguishing localized relaxation from long-range conductivity. J Phys Chem Solids 55:1491-1506. https://doi. org/10.1016/0022-3697(94)90575-4

58. Sinclair DC, West AR (1989) Impedance and modulus spectroscopy of semiconducting $\mathrm{BaTiO}_{3}$ showing positive temperature coefficient of resistance. J Appl Phys 66:3850-3856. https:// doi.org/10.1063/1.344049

59. Law M, Greene LE, Johnson JC et al (2005) Nanowire dye-sensitized solar cells. Nat Mater 4:455-459. https://doi.org/10.1038/ nmat1387

60. Ikeda JAS, Chiang Y-M, Garratt-Reed AJ, Sande JBV (1993) Space charge segregation at grain boundaries in titanium dioxide: II, model experiments. J Am Ceram Soc 76:2447-2459. https://doi. org/10.1111/j.1151-2916.1993.tb03965.x

61. Guo J, Dong $\mathrm{F}$, Zhong $\mathrm{S}$ et al (2018) $\mathrm{TiO}_{2}$-hydroxyapatite composite as a new support of highly active and sintering-resistant gold nanocatalysts for catalytic oxidation of $\mathrm{CO}$ and photocatalytic degradation of methylene blue. Catal Lett 148:359-373. https://doi.org/10.1007/s10562-017-2245-8

62. Singh Vig A, Gupta A, Pandey OP (2018) Efficient photodegradation of methylene blue $(\mathrm{MB})$ under solar radiation by $\mathrm{ZrC}$ nanoparticles. Adv Powder Technol 29:2231-2242. https://doi. org/10.1016/j.apt.2018.06.007
63. Mallakpour S, Hatami M (2018) LDH-VB9-TiO $_{2}$ and LDH-VB9$\mathrm{TiO}_{2} /$ crosslinked PVA nanocomposite prepared via facile and green technique and their photo-degradation application for methylene blue dye under ultraviolet illumination. Appl Clay Sci 163:235-248. https://doi.org/10.1016/j.clay.2018.07.022

64. Pouretedal HR, Kadkhodaie A (2010) Synthetic $\mathrm{CeO}_{2}$ nanoparticle catalysis of methylene blue photodegradation: kinetics and mechanism. Chin J Catal 31:1328-1334. https://doi.org/10.1016/ S1872-2067(10)60121-0

65. Abbasi S, Hasanpour M (2017) The effect of pH on the photocatalytic degradation of methyl orange using decorated $\mathrm{ZnO}$ nanoparticles with $\mathrm{SnO}_{2}$ nanoparticles. J Mater Sci: Mater Electron 28:1307-1314. https://doi.org/10.1007/s10854-016-5660-5

66. Akyol A, Yatmaz HC, Bayramoglu M (2004) Photocatalytic decolorization of remazol red $\mathrm{RR}$ in aqueous $\mathrm{ZnO}$ suspensions. Appl Catal B Environ 54:19-24. https://doi.org/10.1016/j.apcat b.2004.05.021

67. Gonçalves MST, Oliveira-Campos AMF, Pinto EMMS et al (1999) Photochemical treatment of solutions of azo dyes containing $\mathrm{TiO}_{2}$. Chemosphere 39:781-786. https://doi.org/10.1016/S0045 -6535(99)00013-2

68. Daneshvar N, Salari D, Khataee AR (2003) Photocatalytic degradation of azo dye acid red 14 in water: investigation of the effect of operational parameters. J Photochem Photobiol A Chem 157:111-116. https://doi.org/10.1016/S1010-6030(03)00015-7

Publisher's Note Springer Nature remains neutral with regard to jurisdictional claims in published maps and institutional affiliations. 